UMEÅ UNIVERSITY MEDICAL DISSERTATIONS

New Series

No 168

From the Department of Dermatology

Umeå University, Umeå, Sweden

\title{
INDIVIDUAL AND ENVIRONMENTAL RISK FACTORS FOR HAND ECZEMA IN HOSPITAL WORKERS
}

by

Eskil Nilsson

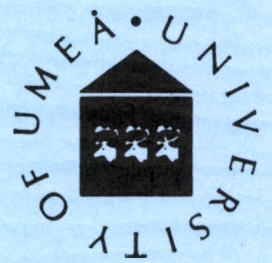

Umeå University 1986 


\section{INDIVIDUAL AND ENVIRONMENTAL RISK FACTORS FOR HAND ECZEMA IN HOSPITAL WORKERS}

Akademisk avhandling som med vederbörligt tillstånd av Rektorsämbetet vid Umeå Universitet för avläggande av medicine doktorsexamen kommer att offentligen försvaras i Rosa Salen, 9tr, Tandläkarhögskolan, Umeå, fredagen den 23 maj 1986, kl. 09.00

Eskil Nilsson

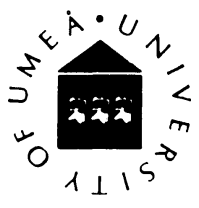

Umeå 1986 


\section{ABSTRACT}

\section{INDIVIDUAL AND ENVIRONMENTAL RISK FACTORS FOR HAND ECZEMA IN HOSPITAL WORKERS}

Eskil Nilsson, Departments of Dermatology, Sundsvall Hospital, S-851 86 Sundsvall and Umeå University, S-901 85 Umeå Sweden.

Individual and environmental risk factors in hand eczema have been investigated in a prospective cohort study of 2452 newly employed hospital workers with a follow-up time of 20 months. Current hand eczema was analyzed in 142 wet hospital workers from this cohort with respect to the etiologic importance of irritants, allergens and contact urticants. The density of the microflora and the effect on the microflora of topical treatment with a potent corticosteroid were studied in 20 patients with hand eczema.

'Wet' hospital work was found to increase the odds of developing hand eczema only twice compared to 'dry' office work. Nursing children under four years old and the lack of a dish-washing machine significantly increased the risk of contracting hand eczema. Unfavourable combinations of these domestic factors increased the risk as much as wet work. A history of atopic dermatitis approximately tripled the odds both in wet as well as in dry work.

Histories of earlier hand eczema (HHE), metal dermatitis (HMD) and of atopy were analyzed as risk factors for hand eczema in 1857 women in wet work. HHE increased the odds by a factor of 12.9 and created a subdivision of the population into high risk individuals and normal risk individuals. HHE was found in half of the subjects with atopic dermatitis, in one quarter of the subjects with atopic mucosal symptoms and in one fifth of the non-atopics. A HMD increased the odds by a factor of 1.8. This increase was seen as a high risk level in subjects with $\mathrm{HHE}$ and as a normal risk level in subjects with no HHE. A history of atopic disease as a complement to information about HHE and HMD increased the odds by another 1.3 times. The predicted probability of developing hand eczema ranged from $91 \%$ in subjects with a combination of $\mathrm{HHE}, \mathrm{HMD}$ and atopy to $24 \%$ in subjects with none of these risk factors.

Subjects with $A D$ were found to suffer a more severe form of hand eczema with significantly higher figures for medical consultation, sickleave, termination due to hand eczema, early debut, permanent symtoms and vesicular lesions.

Amongst the patients investigated for current hand eczema high risk individuals were overrepresented. It was claimed in $92.3 \%$ of the cases that trivial irritant factors had elicited the current episodes of hand eczema. In 35\% of the cases the exposure to the irritant took place largely at home. Although contact sensitivity and contact urticaria were fairly common, they mostly seemed to be of minor importance in the etiology of the current hand eczema.

Staphylococcus aureus colonized eczematous lesions of the hands in $18 / 20$ patients. The density exceeded 105 colony forming units $/ \mathrm{cm}^{2}$ in $15 / 20$ patients. Only three of these patients showed signs of clinical infection. Successful topical treatment with a potent corticosteroid significantly reduced the colonization of $\mathrm{S}$. aureus.

Key words: Hand eczema, prospective study, hospital workers, irritants, contact allergy, contact urticaria, atopy, metal dermatitis, multivariate regression analysis, evaluation of risk factors, microflora, S. aureus in hand eczema. 
UMEÅ UNIVERSITY MEDICAL DISSERTATIONS

New Series

No 168

From the Department of Dermatology

Umeå University, Umeå, Sweden

\section{INDIVIDUAL AND ENVIRONMENTAL RISK FACTORS FOR HAND ECZEMA IN HOSPITAL WORKERS}

by

Eskil Nilsson

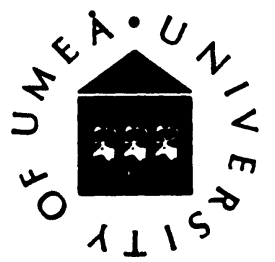




\section{A B S T R A C T}

INDIVIDUAL AND ENVIRONMENTAL RISK FACTORS FOR HAND ECZEMA IN HOSPITAL WORKERS

Eskil Nilsson, Departments of Dermatology, Sundsvall Hospital, S-851 86 Sundsvall and Umeå University, S-901 85 Umeå, Sweden.

Individual and environmental risk factors in hand eczema have been investigated in a prospective cohort study of 2452 newly employed hospital workers with a follow-up time of 20 months. Current hand eczema was analyzed in 142 wet hospital workers from this cohort with respect to the etiologic importance of irritants, allergens and contact urticants. The density of the microflora and the effect on the microflora of topical treatment with a potent corticosteroid were studied in 20 patients with hand eczema.

'Wet' hospital work was found to increase the odds of developing hand eczema only twice compared to 'dry' office work. Nursing children under four years old and the lack of a dish-washing machine significantly increased the risk of contracting hand ezcema. Unfavourable combinations of these domestic factors increased the risk as much as wet work. A history of atopic dermatitis approximately tripled the odds both in wet as well as in dry work.

Histories of earlier hand eczema (HHE), metal dermatitis (HMD) and of atopy were analyzed as risk factors for hand eczema in 1857 women in wet work. HHE increased the odds by a factor of 12.9 and created a subdivision of the population into high risk individuals and normal risk individuals. HHE was found in half of the subjects with atopic dermatitis, in one quarter of the subjects with atopic mucosal symptoms and in one fifth of the non-atopics. A HMD increased the odds by a factor of 1.8. This increase was seen as a high risk level in subjects with HHE and as a normal risk level in subjects with no HHE. A history of atopic disease as a complement to information about HHE and HMD increased the odds by another 1.3 times. The predicted probability of developing hand eczema ranged from $91 \%$ in subjects with a combination of HHE, HMD and atopy to $24 \%$ in subjects with none of these risk factors.

Subjects with $A D$ were found to suffer a more severe form of hand eczema with significantly higher figures for medical consultation, sick-leave, termination due to hand eczema, early debut, permanent symptoms and vesicular lesions.

Amongst the patients investigated for current hand eczema high risk individuals were overrepresented. It was claimed in $92.3 \%$ of the cases that trivial irritant factors had elicited the current episodes of hand eczema. In $35 \%$ of the cases the exposure to the irritant took place largely at home. Although contact sensitivity and contact urticaria were fairly common, they mostly seemed to be of minor importance in the etiology of the current hand eczema.

Staphylococcus aureus colonized eczematous lesions of the hands in $18 / 20$ patients. The density exceeded $10^{5}$ colony forming units $/ \mathrm{cm}^{2}$ in $15 / 20$ patients. Only three of these patients showed signs of clinical infection. Successful topical treatment with a potent corticosteroid significantly reduced the colonization of $S$. aureus.

Key words: Hand eczema, prospective study, hospital workers, irritants, contact ailergy, contact urticaria, atopy, metal dermatitis, multivariate regression analysis, evaluation of risk factors, microflora, $S$. aureus in hand eczema. 
This thesis is based on the following papers, which will be referred to by their Roman numerals:

I. Nilsson E, Mikaelsson B, Andersson S. Atopy, occupation and domestic work as risk factors for hand eczema in hospital workers.

Contact Dermatitis 1985:13:216-223.

II. Nilsson E, Bäck 0 .

The importance of anamnestic information of atopy, metal dermatitis and earlier hand eczema for the development of hand dermatitis in women in wet hospital work. Acta Dermato-Venereologica 1986:66:45-50.

III. Nilsson E.

Contact sensitivity and urticaria in "wet" work.

Contact Dermatitis 1985:13:321-328.

IV. Nilsson E, Henning C, Hjörleifsson M-L. The density of the microflora in hand eczema before and after topical treatment with a potent corticosteroid. $\mathrm{J}$ Amer Acad Dermatol. In press. 
ABBREVIATIONS.................................. 6

INTRODUCTION................................. 7

REVIEW OF THE LITERATURE........................ 7

HAND ECZEMA..................................... 7

Prevalence......................................... 7

Classification............................... 8

ATOPIC DERMATITIS............................. 9

Epidemiology.................................. 9

Diagnosis.................................. 9

Hand eczema in atopic dermatitis................. 11

EXOGENOUS FACTORS IN HAND ECZEMA................... 12

Irritants.................................. 12

Allergic contact dermatitis of the hands........... 14

Atopy and contact sensitivity.................. 15

Contact urticaria........................... 16

Non-Immunological Contact Urticaria (NICU)......... 17

Immunological Contact Urticaria (ICU) ............... 17

Uncertain Mechanism Mediated Contact Urticaria (UMCU). 18

Contact urticaria in hand eczema................... 18

Colonization of Staphylococcus aureus.................. 19

AIMS OF THE STUDY............................ 21

PATIENTS.................................. 22

Study design and study population (I-II) $\ldots \ldots \ldots \ldots \ldots, 22$

Patients (III) ................................ 23

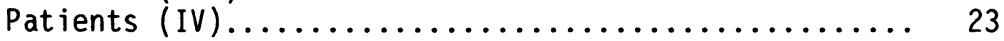

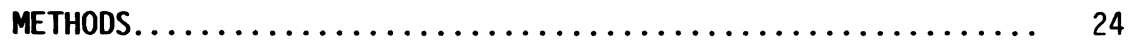

PAPERS I-II.............................. 24

Diagnosis of atopy and metal dermatitis.............. 24

Criteria for hand eczema......................... 24

Occupational exposure............................ 25

Domestic work................................. 25

Statistical methods............................. 26

PAPER III................................ 27

Characterization of hand eczema.................. 27

Patch tests............................... 28

Prick tests.................................. 28

Statistics............................. 28 
PAPER IV..................................... 29

Characterization of hand eczema................... 29

Sampling technique........................... 29

Identification of the microflora.................... 30

Treatment........................................ 31

Antibacterial effect of clobetasol propionate........ 31

Statistics................................ 31

RESULTS.................................... 32

Prevalence of individual risk factors............ 32

Hand eczema in the four occupations................ 32

Hand eczema in atopics....................... 33

Hand eczema in women in wet hospital work.......... 35

Multivariate regression analys is of risk factors..... 37

Severity of hand eczema..................... 43

Investigated patients (III) $\ldots \ldots \ldots \ldots \ldots \ldots \ldots \ldots \ldots, 45$

Earlier hand eczema in investigated patients......... 45

Current hand eczema in investigated patients.......... 45

State of current hand eczema...................... 46

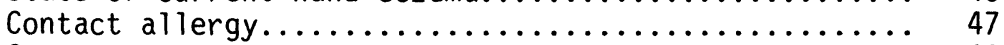

Contact urticaria........................................... 48

Morphology of hand eczema in the bacteriological study

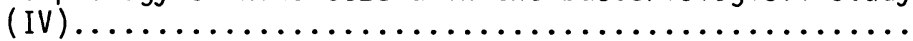
Microbial fiora and effect of treatment.............. 53

DISCUSSION.................................... 56

The cohort and patients studied............... 56

Methodological aspects.......................... 56

Prevalence of hand eczema...................... 58

Prevalence of atopy and metal dermatitis............ 58

Individual risk factors for hand eczema............ 59

Severity of hand eczema........................ 61

Occupational and domestic factors in hand eczema...... 61

Contact allergy and hand eczema................. 62

Contact allergy to metals in subjects with metal der-

matitis............................... 63

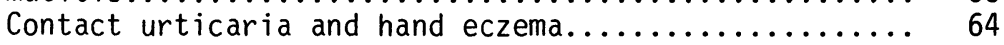

Staphylococcus aureus in hand eczema.................. 66

SUMMARY AND CONCLUSIONS......................... 70

ACKNOWLEDGEMENTS.................................... 73

REFERENCES................................ 74 


\section{A B B R E V I A T I O N S}

AD Atopic dermatitis

AMS Atopic mucosal symptoms

NA Non-atopics

HMD History of metal dermatitis

HHE History of earlier hand eczema

OR Odds ratio

PP Predicted probability 


\section{NTROD U C T I O N}

Hand eczema is a disorder of multifactorial etiology. There is general agreement that individual and environmental factors may interact in a complex manner to elicit this common disorder. To date knowledge of the interplay between endogenous and exogenous factors is very limited. Extending this knowledge must be considered a high priority task in the struggle to discover the nature of hand eczema. There are many advantages to be gained from an improved understanding of the relative importance of individual and environmental factors. The accurate classification of hand eczema, occupational counselling, medico-legal considerations, prognostic speculations and the outcome of therapeutic measures are all dependent on the extent to which endogenous and exogenous factors contribute to the etiology of hand eczema. This study has been designed to throw some light on this complex problem.

\section{REV I EW OF THE L I TERATURE}

\section{HAND ECZEMA}

Prevalence. Epidemiological studies of hand eczema in various populations have recorded a rather wide range of prevalence figures. Agrup (1) estimated that the prevalence of hand dermatitis in the general population in southern Sweden was 1.2-3.4\%. As a part of a study on nickel allergy Peltonen (2) examined the hands of 980 subjects in Finland and found hand eczema in $4 \%$. In a study in northern Norway (3) 14.667 adult subjects were asked about the occurrence of allergic hand eczema during the preceding twelve months. A positive reply was given by $4.9 \%$ of the men and $13.2 \%$ 
of the women. The age of the women influenced the prevalence. Thus $15 \%$ of women between 25-34 years of age reported hand eczema while for women between 45-49 years the figure was only $9.2 \%$. In a prevalence study in the Netherlands an episode of eczema of the hands and forearms lasting for three weeks and occurring during the past three years was used as a criterion for a case of hand eczema. In this study the prevalence figures for 1982 were $4.5 \%$ for men and $10.0 \%$ for women (4). A representative sample consisting of 1961 Danish women reported a history of hand eczema in $22 \%$ (5). In a Finnish study of 617 wet hospital workers, predominantly women, $44 \%$ had past or present hand eczema (6).

The various results recorded in these investigations reflect some of the problems innate in prevalence studies of hand eczema. As hand eczema is a periodic disorder figures based on a single examination will underrate the prevalence. Prevalence studies covering periods of time must rely on anamnestic information with its limitations regarding accuracy of diagnosis. Another aspect of the problem is how severe a dermatitis of the hands has to be before it can be diagnosed as ezcema. The difference in prevalence between the two sexes and the importance of wet work is obvious from the figures.

Classification. Classification of hand eczema may be based on the morphologic description of the eczema with terms such as vesiculous-sqamous, nummular, wedding-ring, fingertip, hyperkeratotic and pompholyx (7). These names refer to clinical features and say very little or nothing about the etiology. A common way to classi- 
fy hand ezcema is according to etiologic aspects. Thus the terms irritant or allergic contact dermatitis of the hands are used depending on the cause.

As stated by Epstein hand eczema is almost always multifactorial and therefore simple etiologic classifications are doomed to failure. In order to avoid the frustrating struggle with some of the classifications Epstein proposed that hand eczema should be analyzed for its endogenous and exogenous factors (8).

\section{ATOPIC DERMATITIS}

Epidemiology. The incidence of atopic disease varies widely in the great number of existing investigations. A very complete survey of this topic has been given elsewhere (6). Differences in diagnostic criteria and selection of the population studied regarding age, race and geographic distribution are all probable explanations for the differences found. The cumulative incidence of atopic disease varies from $15-25 \%$ in most reports (9). In a study on 7000 adult twin pairs in Sweden $18 \%$ had or had had atopic disease (10). In another Swedish study on 1325 unselected 7-year-old school children $15.1 \%$ had atopic disease and $8.3 \%$ had or had had atopic dermatitis (11).

Diagnosis. Attempts to define this dermatological disorder were made as early as in 1892 when Besnier (12) observed a familial disposition and noted that the disorder which he named prurigo diathésique occurred in association with allergic rhinitis, asthma 
and sometimes gastrointestinal symptoms. The term atopy was introduced by Coca \& Cooke in 1923 and means a strange disease (13). The word is Greek and can be translated as 'out of place'. In modern terminology the term atopy includes allergic rhinoconjunctivitis, bronchial asthma, atopic dermatitis, and certain forms of gastrointestinal allergy and urticaria.

A transferable factor was found in the serum of allergic persons by Prausnitz \& Kuistner in 1921 (14). This transferable factor has been identified as immunoglobulin $E$ ( $\mathrm{IgE}$ ) and methods have been developed to measure the total and specific amount of IgE (1519). Atopic individuals are commonly defined as having an increased liability to form IgE antibodies when exposed to environmental antigens. This commonly used generalization is true for allergic rhinitis and allergic asthma but not for atopic dermatitis. The dermatitis which occurs in atopics is not a typical atopic disease since the importance of allergic factors is uncertain (20-22). Approximately $20 \%$ of patients with severe flexural eczema have normal serum IgE levels (22).

No absolute diagnostic criteria exist for atopic dermatitis. Diagnostic guidelines have been proposed by Hanifin \& Rajka (23). These guidelines are based on a few basic and many minor criteria. Lammintausta introduced a prognostically useful definition of the skin condition in subjects with atopic mucosal symptoms and nonatopics. This condition was named atopic skin diathesis and was defined as follows: 
a) dry skin

b) a history of a low pruritus threshold for two or three of the following non-specific irritants: sweat, dust, rough material

c) white dermographism and

d) facial pallor/infraorbital darkenings

Atopic skin diathesis was found in $35 \%$ of the subjects with atopic mucosal symptoms and in $18 \%$ of the non-atopics. This diathesis was found to significantly increase the risk of hand eczema among employees engaged in wet work (6).

Hand eczema in atopic dermatitis. Several reports exist in which a correlation has been found between hand eczema and a personal or family history of atopy $(1,24-29)$. Atopic disease and especially atopic dermatitis in childhood as risk factors for hand eczema in adults have been the subject of two large studies during the last few years. One study has been carried out by Lammintausta on wet hospital workers in Turku, Finland (6) and the other by Rystedt on selected groups of atopics in Stockholm, Sweden (9). In both studies an increased risk of developing hand eczema was found in subjects who had had atopic dermatitis in childhood. Both authors also found that a considerable number of subjects with earlier atopic dermatitis managed to work in high risk occupations without developing hand eczema. Atopic skin diathesis, as defined by Lammintausta, significantly increased the risk of hand eczema in subjects with atopic mucosal symptoms and in non-atopics. In subjects with atopic dermatitis Rystedt identified the following cli- 
nical markers as significantly increasing the risk of hand eczema: eczematous involvement of the hands in childhood, widespread dermatitis in childhood, persistent body eczema and dry/itchy skin. In subjects with atopic mucosal symptoms and in non-atopic individuals it was found that dry/itchy skin significantly increased the risk of hand eczema (9). Neither of these two studies was prospective and it was not possible to calculate the relative importance of individual versus environmental risk factors in the development of hand eczema.

\section{EXOGENOUS FACTORS IN HAND ECZEMA}

Irritants. The first line in the capacity of the skin to protect itself against external exposure is the surface film, sometimes called the acid mantle because its $\mathrm{pH}$ is on the acid side (30). The buffer capacity of the surface film varies amongst individuals and also from one body region to another $(31,32)$. The main protective function in the skin rests with the stratum corneum (3234 ). The flexibility and cohesion of the horny layer are dependent on the water content (35-36). Reduction of the water-holding substances will decrease the water content of the stratum corneum and cracks and chapping will develop (37-39). Cell-wall lipids protect the water-holding substances (40). Detergents remove lipids and water-holding substances and cause a predisposition to chapping $(35,41)$. A breakdown of the natural resistance of the skin leads to increased water vapor loss and the integrity of the skin barrier can be measured by transepidermal water loss $(42-44)$. 
Acute irritant dermatitis may be caused by strong irritants after a single or a few applications. Hand eczema may also occur after repeated assaults by weak irritants over a long period of time. This dermatitis has been named 'wear and tear' dermatitis and 'traumiterative dermatitis' (45). There is no test which can determine whether an irritant is relevant to a patient's dermatitis. Thus the evaluation of the relative importance of irritants in patients with hand eczema has to be a clinical decision. Discussions of irritants are usually focused on chemicals, solvents, acids, alkali and surfactants. However, dry air, low humidity, cold, wind and friction may be important contributory factors (8). It is very difficult to obtain scientific documentation of the widely-held opinion that contact with irritants is the most common cause of hand eczema. Clinical evidence that surfactants aggravate hand eczema is, however, overwhelming (8). Thus various kinds of wet work involve occupational hazards to the hands (29, 46-50).

Some people seem particularly prone to develop irritant dermatitis $(51,52)$. Irritable skin seems to depend on constitutional factors but so far it has not been possible to identify individuals who are particularly susceptible to irritants (53). Long clinical experience has shown that atopic skin has a reduced resistance to irritants and consequently has an increased tendency to develop irritant dermatitis especially on the hands. According to the recent findings by Lammintausta and Rystedt this reduced resistance does not seem to occur in all subjects with a history of atopic dermatitis as a considerable number managed to work in risk occupations without developing hand eczema $(6,9)$. In subjects 
with atopic mucosal symptoms and in non-atopics Lammintausta identified atopic skin diathesis which was found to increase the risk of irritant hand eczema (6). These observations indicate that a reduced resistance to irritants does not occur in all subjects with atopic dermatitis and may occur in subjects with atopic mucosal symptoms and in non-atopics.

Allergic contact dermatitis of the hands. A lot of interest has been focused on delayed contact sensitivity in the etiology of hand eczema. Figures for allergic contact dermatitis among hand eczema patients vary considerably $(1,29,54)$. The most important reason for this variation is probably the selection of the patient populations tested. A positive patch test in a patient with hand eczema does not mean that a contact allergy is relevant for the current hand dermatitis. Judging the relevance of a positive patch test in hand eczema may be very difficult. An allergen is considered a primary cause of the dermatitis if elimination leads to a complete cure. It is only too common for an allergen to be of doubtful relevance. The proven contact allergy may be only a contributory or aggravating factor or of no significance at all to the dermatitis.

There has been no prospective study on the importance of a delayed contact allergy as a risk factor in hand eczema. A retrospective study on wet hospital workers found that hand eczema was significantly more common amongst subjects with contact allergy. However, a considerable number of workers with contact sensitivity to nickel and fragrance mix had managed to work without deve- 
loping hand eczema (6). Amongst hospital workers the following sensitizers are reported to be common: rubber gloves, formaldehyde, chloroxylenol, penicillin, streptomycin, neomycin, piperazine, phenothiazines, hand creams, nickel and glutaraldehyde (55).

Atopy and contact sensitivity. Delayed hypersensitivity to candida, trichophytin, tuberculin and other bacterial and viral antigens is diminished in patients with atopic dermatitis (56-61). Dinitrochlorobenzene (DNCB) which sensitizes over $90 \%$ of the normal population has been found to sensitize a lower proportion of atopic patients $(56,62-64)$. Sensitivity to RHUS-antigen was found in $15 \%$ of atopics whereas $61 \%$ of non-atopics were sensitized (65).

The occurrence of delayed contact dermatitis and positive patch tests in patients with atopic dermatitis is a subject which produces contradictory findings. One study found a positive patch test reaction in $28 \%$ of $A D$ patients as compared to $9 \%$ of psoriatics (66). In another study on 4000 patients, of whom 233 had atopic dermatitis, a positive patch test reaction was no more frequent in the atopics (26). Most studies on the prevalence of contact sensitivity in patients with atopic dermatitis have produced figures between $15 \%$ and $35 \%(1,6,26,67,68)$. Some investigators have found nickel allergy to be more common in atopic individuals (69-71) whereas other investigators have found no such correlation (72-75). Judging the relevance of a positive patch test in a patient with hand eczema may be even more frustrating in atopics than in non-atopics. In atopics it must be assumed that endogenous factors and an increased sensitivity to 
irritants play an important part in the etiology of the hand eczema. Forsbeck et al. (28) found that contact allergy was as common in $A D$ patients without hand eczema as in patients with hand eczema. This finding highlights the problem of the relevance of contact allergy in subjects with atopic dermatitis and hand eczema.

Contact urticaria. Contact urticaria (CU) may be defined as a wheal-and-flare response elicited from within a few minutes up to half an hour after skin exposure to various agents. The term (contact urticaria syndrome) was proposed in 1975 to cover a broad spectrum of clinical manifestations which may be provoked by the causative agent (76). The following staging for this syndrome is proposed by von Krogh \& Maibach (77).

Cutaneous reactions only:

Stage 1: localized urticaria dermatitis non-specific symptoms (itching, tingling, burning etc)

Stage 2: generalized urticaria

Extracutaneous reactions:

Stage 3: bronchial asthma rhinoconjunctivitis oro-laryngeal symptoms gastro-intestinal symptoms

Stage 4: anafylactoid reactions 
Non-Immunological Contact Urticaria (NICU). In NICU the reaction is elicited without previous sensitization in most exposed individuals. A release of histamine and other vasoactive substances without involving immunological mechanisms is thought to be the cause (78). This type of contact urticaria is probably very common. Many chemicals in common use have the ability to provoke NICU in a large number of normal individuals (77). Agents such as benzoic acid, sorbic acid, cinnamic acid and cinnamic aldehyde are potent urticariogenic substances. When exposure is optimal a majority of individuals will react with contact urticaria after application of rather high concentrations to intact skin. In lower concentration they may provoke erythema but not a true urticarial reaction. Thus the frequency and strength of NICU are influenced by the concentration of the individual chemicals and even by the chemical composition of the vehicle (79).

Immunological Contact Urticaria (ICU). Evidence of an allergic mechanism in contact urticaria has been rare. Immunological mechanisms may be suspected when there has been a period of sensitization, the reaction is strong, tests on controls are negative and passive transfer test is positive. IgE specific for the antigen has been found in some cases (80-83). Urticaria may also be caused by allergic mechanisms in which specific immunoglobulin $G$ and perhaps immunoglobulin $M$ may activate the complement cascade through the classical pathway $(84-86)$. 
While atopics and non-atopics do not differ with respect to NICU (79) it is likely but poorly documented that ICU is more common among atopics.

Uncertain Mechanism Mediated Contact Urticaria (UMCU). This type of contact urticaria refers to reactions for which the mechanisms are unknown (77). Von Krogh \& Maibach have updated the contact urticaria syndrome and listed most of the substances known to elicit contact urticaria in the three groups $(77,87)$.

The diagnosis of contact urticaria had to be based on a careful history of immediate reactions. Diagnostic tests guided by the case history may be performed on intact skin as open, occlusive or intradermal and on slightly affected or previously affected skin as open or occlusive tests. A stepwise test procedure has been recommended by von Krogh \& Maibach $(77,87)$.

Contact urticaria in hand eczema. In a study of 33 food-handlers with recurrent hand eczema it was found that exposure of the hands to various proteins aggravated the hand eczema. Itching, erythema, urticarial swelling and dyshidrotic vesicles were observed within 10-30 minutes after contact between the incriminating protein and the affected skin. Contact urticaria was found in 9 cases of whom 3 reacted only when the suspected food was exposed to eczematous skin. In total 25 showed a positive scratch test with food such as chicken, seafood, vegetables and spices. The term 'protein contact dermatitis' was introduced to describe this phenomenon (88). Immediate reactions which aggravate chronic hand dermatitis 
have been reported by other authors. Thus lettuce and endive (89), wheat flour, turkey and lamb (90) and apple and potato (91) have been found to aggravate or elicit hand dermatitis. Some of the patients in these studies reacted with positive tests only on previously dermatitic skin or after intradermal tests.

Although case reports on contact urticaria are numerous the epidemiology in the general population and in populations with hand eczema is unknown except for the study on food-handlers by Hjorth \& Roed-Petersen (88).

Colonization of Staphylococcus aureus. The nose, axillae, perineum and toe-webs are the only common resident carrier sites of $\underline{S}$. aureus on human skin. Normal skin from other locations yields $\underline{S}$. aureus in about $5 \%$ of the population (92). Higher carrier rates will be found when individuals are followed up over periods of

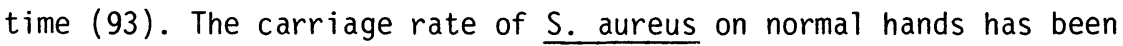
studied in various populations. In $13 \%$ of nasal carriers S. aureus was cultured by the 'fingerprint' technique compared to $4 \%$ of noncarriers (94). In a study of 361 patients prepared for operation it was found that $24 \%$ carried S. aureus on their hands (95). Among hospital staff who had just completed a ward round or treatment $68 \%$ carried S. aureus on their hands compared with $25 \%$ of those engaged in other duties in the same ward or who had just washed their hands (96). A study on 50 nurses and 50 controls found that $28 \%$ of both groups carried S. aureus on their hands. The mean density was however lower among the nurses. A higher percentage of the nurses carried $\underline{\mathrm{S} \text {. aureus }}$ on their hands persistently during a three-month period (97). 
Various dermatitic conditions carry $\underline{S}$. aureus more frequently than normal skin. Candidiasis in intertriginous regions carries S. aureus in $60 \%$ (98), psoriatic plaques are colonized with $\underline{S}$. aureus in $20-50 \%(99-102)$. In a review article by Leyden (103) the following frequency and density of $\underline{S}$. aureus were reported in various dermatitic conditions: seborrhoic dermatitis $21 \%$ with a density of $13000 \mathrm{cfu} / \mathrm{cm}^{2}$, neurodermatitis $90 \%$ with $600000 \mathrm{cfu} /$ $\mathrm{cm}^{2}$, exfoliative erythroderma $100 \%$ with $2000000 \mathrm{cfu} / \mathrm{cm}^{2}$, chronic familial benign pemphigus $90 \%$ with $4000000 \mathrm{cfu} / \mathrm{cm}^{2}$ scaling interdigital athlete's foot $6 \%$ with $30000 \mathrm{cfu} / \mathrm{cm}^{2}$, macerated interdigital athlete's foot $11 \%$ with $500000 \mathrm{cfu} / \mathrm{cm}^{2}$. Dermatitic skin in atopics has shown both a high carriage rate and high counts of S. aureus $(104,105)$. Although it is well-known from clinical experience that $\underline{S}$. aureus is commonly isolated from eczematous lesions of the hands no systematic quantitative study has been performed on the microflora of hand eczema. 


\section{A I MS OF THE STUDY}

1. Epidemiological: To investigate the relative importance of some individual and environmental factors in the etiology of hand eczema in newly employed hospital workers.

2. Clinical: To study the importance of irritants, allergens and contact urticants in a selected group of newly employed wet hospital workers with hand eczema.

3. Bacteriological: To study the density of the microbial flora and i.e. S. aureus in hand eczema and the effect on the microflora of a potent topical corticosteroid. 


\section{P A T I E N T S}

Study design and study population (I-II). The study has been performed as a prospective cohort study. The cohort was collected from June 1979 to June 1981 and consisted of 2651 newly employed workers in four hospitals in the county of Västernorrland in northern Sweden. At the preemployment examination, previous skin diseases were recorded but played no part in the selection for employment. A follow-up questionnaire was sent to the employees and answers were received from 2452 subjects (92.5\%) after a median observation time of 20 months (range 18.5-24.0). The frequency of atopic disease in the defaulters did not differ from that found in the total cohort. Table I shows the number of employees, percentage of females and median age of the occupational groups. Nursing staff included all kinds of staff working with patients. The following subgroups were included: ward maids 964, nurses/ assistants 233, psychiatric nurses 122, nursing assistants 117 , physicians 55 , children's nurses 36 , dental staff 31 , occupational therapists 36 and chiropodists 1. Nursing staff and kitchen workers/cleaners performed wet work while office workers and caretakers/craftsmen performed mainly dry work.

Table I. Number of employees, sex and median age in the occupational groups

\begin{tabular}{lccc}
\hline & Number & Female (\%) & Median age \\
\hline Nursing staff & 1613 & 87.7 & 25 \\
Kitchen workers/cleaners & 457 & 93.4 & 23 \\
Office workers & 269 & 91.8 & 22.5 \\
Caretakers/craftsmen & 113 & 16.8 & 29
\end{tabular}


Patients (III). The patients in this study consisted of 142 subjects from the total cohort employed in hospital wet work who consulted a dermatologist because of current hand eczema. $91 \%$ of them were women and the mean age was 26.2 years. $72 \%$ were employed in nursing occupations, $16 \%$ were cleaning personnel and $12 \%$ were kitchen workers.

Patients (IV). Twenty patients, 16 females and 4 males, with hand eczema were studied. The age of the patients ranged from 13-61 years. Patients who had received local or systemic antibiotics or local corticosteroids within the last two weeks were excluded as were patients with severe suppuration, tenderness, adenopathy and fever. 


\section{METHODS}

\section{PAPERS I-II}

Diagnosis of atopy and metal dermatitis. At the preemployment examination any history of atopic disease was noted by a specially trained occupational nurse in a standardized manner. Atopic dermatitis was accepted as a diagnosis if there was a history of itching, relapsing dermatitis starting in infancy or childhood with a typical distribution. Subjects with past or present atopic dermatitis were recorded together. Atopic mucosal symptoms were accepted as a diagnosis if hayfever or asthma occurred when the subject was exposed to pollen or furred animals. No other diagnostic tests or criteria for atopic disease were used.

A history of metal dermatitis was derived from a questionnaire in which the employees were asked about an itching rash related to exposure to metal buttons, cheap jewelry or wristwatches.

Criteria for hand eczema. At the preemployment examination the employee was informed that the study concerned hand eczema and was given some brief information about the symptomatology of hand dermatitis. The occurrence of hand eczema during the period studied was identified in the follow-up questionnaire. The employee was then asked to characterize his/her eczema using one or more of the following five alternatives:

1. dry and chapped skin with rashes and small cracks

2. itching red macular and papular skin lesion

3. small vesicles 


\section{4. ruptured vesicles or excoriated skin \\ 5. rough skin with cracks and scaling}

The employee was asked about medical consultation, sick-leave and if he/she had left his/her current work because of hand eczema. The time of onset and the nature, periodic or permanent, of the eczematous symptoms were also recorded. Those who had stated in the questionnaire that they had suffered from hand eczema without seeking medical advice were asked why they had not done so. In a separate question the employee was asked about hand eczema prior to the current work. The reliability of identification of hand eczema by questionnaire has been checked in this study using 146 patients who attended the dermatological clinic with a hand dermatitis which they suspected was eczema. Of these patients, only four had diagnoses other than eczema. One had palmar keratoderma, two had pustular dermatosis of the palms and one had scabies.

Occupational exposure. Approximately $50 \%$ of the employees worked part-time and $1 / 3$ had changed their work for other occupations at the follow-up.

Domestic work. Six anamnestic parameters which reflect domestic manual work from different points of view were recorded: the nursing of children younger than four years of age; members of the household; hours of housekeeping per week; hours per week spent working with the hands on a hobby; use of washing machine and dish-washer. The purpose was to investigate the correlation between these parameters and the risk of developing hand eczema. 
Statistical methods. The multifactorial problem in this study has been analyzed using a multivariate logistic regression technique (106). The risk of developing hand eczema was calculated as predicted relative odds ratios. The odds ratio (OR) expresses the relationship between the odds (01) of getting hand eczema (E1) in one group $(01=E 1 /(1-E 1))$ compared to odds (02) of hand eczema (E2) in a second group $(02=E 2 /(1-E 2))$. E1 and E2 denote the proportion of hand eczema in the two groups. Then the odds ratio (OR) will be

$$
O R=02 / 01=E 2(1-E 1) / E 1(1-E 2)
$$

The risk in per cent of developing hand eczema has been statistically calculated and is expressed as predicted probability (PP).

The Student's $\underline{t}$-test was used to compare relative frequencies.

Three multivariate regression analyses of the interrelationship between individual and environmental factors will be presented. The following factors were used in the three analyses.

The first analysis (A1): $A D$, AMS, NA and occupation.

The second analys is (A2): AD, AMS, NA, domestic factors and the three occupations dominated by women.

The third analysis (A3): AD, AMS, NA, HMD and HHE in women in wet hospital work. 


\section{PAPER III}

Characterization of hand eczema. The following factors regarding hand eczema prior to the present work were recorded: time from onset, periodicity and occupation at onset. The patients' opinions about factors which elicited the current hand eczema and contact urticaria were sought. The state of the current hand eczema and diagnosis of ongoing eczema at sites other than the hands, were noted.

Patch tests. Epicutaneous testing was carried out on 120/142 patients using the European standard series except for caine mix and fragrance mix. Benzalconium chloride $0.1 \%$ and coal tar $5 \%$ were added to the standard series.

An additional series of agents was tested on 55/120 consecutive patients. This series consisted of disinfectants, preservatives, emollients, perfumes and colourings. Most of these were present in products in common use in the hospitals. The following were included: lauromacrogol as it is, macrogol as it is, carbopol 1\%, EDTA $1 \%$, propyl gallate $1 \%$, sorbic acid $2.5 \%$, triethanolamine $5 \%$, chlorocresol 2\%, merthiolate $0.1 \%$, chloracetamide $0.1 \%$, patent blue $\mathrm{V} 2 \%$, quinoline yellow $2 \%$, ethanolamine $5 \%$, chlorhexidine gluconate $1 \%$, BHT $2 \%$, bronopol $1 \%$, propylene glycol $20 \%$, isopropyl myristate $20 \%$, cetyl alcohol $5 \%$, cetrimide $0.1 \%$ and $0.01 \%$, eucalyptol $2 \%$ and hexachlorophene $1 \%$. The European standard test series was supplemented with the addition of caine mix and fragrance mix when testing these 55 consecutive patients. 
The Finn Chamber technique was used with exposure to the allergen for 48 hours. The tests were read after 72 hours.

Prick tests. For contact urticaria, prick tests were carried out as open tests on the upper back. They were read after 15-30 min. Histamine was included as a positive and saline as a negative control. If the mean diameter of the wheal subtracted from the negative reference was $3 \mathrm{~mm}$ or more, the reaction was regarded as positive. Prick tests were performed on 41 out of 49 patients with a positive history. Eight patients declined to have prick tests for various reasons.

A screening series for contact urticaria was conducted as a supplement to substances suspected from case histories. Included in the 'hospital screening series' were three chemically identified substances (formaldehyde $2 \%$, benzalconium chloride $0.1 \%$ and isopropyl myristate $20 \%$ ). The test series included some complex chemicals and agents which were all in common use in the hospitals: i.e. two liquid soaps (Blido, Barnängen); three disinfectants (hand spirit, M-spirit and Hibiscrub); four emollients (Atrix, Sumabless, Helosan and Calmuril), a green rubber glove and a paper towel which was tested wet.

Statistics. Student's $\underline{t}$-test was used to compare relative frequencies. A significance level of $5 \%$ was chosen. 


\section{PAPER IV}

Characterization of hand eczema. The eczema was characterized by: erythema, papules, infiltration, vesicles, erosions, fissures, crusts and signs of clinical infection with exsudation and yellow crusts. The extension of the lesion was estimated and recorded as small $(<1 / 3)$, medium $(1 / 3-2 / 3)$ and large $(>2 / 3)$ in relation to the total area.

Sampling technique. The sampling technique of Williamson \& Kligman (107) was employed with some modification. A sterile silicone rubber cylinder (inner area $5.3 \mathrm{~cm}^{2}$ ) was placed on the sampling site of the skin and filled with $2 \mathrm{ml} 0.1 \%$ Triton $X-100$ in $0.075 \mathrm{M}$ phosphate buffered saline pH 7.9. After scrubbing for one minute with a disposable $10 \mu \mathrm{l}$ inoculating loop (Nunc A/S, Roskilde, Denmark) the liquid was transferred to a locally-produced anaerobic transport device. To facilitate sampling from the fingers a special sampling device was constructed. In a piece of silicone rubber tubing (length $60 \mathrm{~mm}$, inner diameter $20 \mathrm{~mm}$ ) two holes with a diameter of $14 \mathrm{~mm}$ for thick fingers or $11 \mathrm{~mm}$ for thin fingers were cut opposite each other. The sampling device was mounted on a finger, and filled with the detergent buffer. The oval enclosed on a finger of $14 \mathrm{~mm}$ diameter was $3.89+/-0.26 \mathrm{~cm}^{2}$ (mean $+/-\mathrm{SD}$ of 4 experiments) and that on a finger of $11 \mathrm{~mm}$ diameter 3.37 $+/-0.21 \mathrm{~cm}^{2}$. In finger samples an estimated area of $3.6 \mathrm{~cm}^{2}$ was used in all calculations regardless of finger diameter. Before treatment, samples were taken from three sites; 1) from the most pronounced eczematous lesions; 2) from skin affected only with 
erythema and 3) from clinically normal skin of the hands. After treatment the same skin areas were resampled.

Identification of the microflora. The samples were diluted tenfold $\left(10^{-1}, 10^{-2}, 10^{-3}\right)$ in peptone yeast broth (108) and plated in an anaerobic glove box. Brain Heart Infusion Agar (BHIA), Lab $M$, London, England; Trypticase Soy Agar (TSA), Difco, Detroit, Michigan, USA; and TSA + 0.5\% Tween 80, Kebo Lab, Stockholm, Sweden, were incubated aerobically at $37^{\circ} \mathrm{C}$ for two days and BHIA also anaerobically at $37^{\circ} \mathrm{C}$ for five days. All bacterial colonies with different morphology were quantified from the appropriate dilution and identified when the number of colony forming units (cfu) reached $10 / \mathrm{cm}^{2}$, which was the technical boundary of quantitative estimation. Coagulase-negative staphylococci were identified according to the simplified scheme of Kloos \& Schleifer (109). Staphylococci were separated from micrococci by their ability to produce acid aerobically from glucose (110). Corynebacteria were divided into lipophilics and non-lipophilics by the growth of lipohilics on TSA + 0.5\% Tween 80 (111). Peptostreptococci, propionibacteria and Sarcina sp. were identified according to the VPI Anaerobe Laboratory Manual (108).

Before quantitative bacteriological analyses different bacterial species were combined into three main groups: (1) S. aureus., other aerobes, and (3) anaerobes. 
Treatment. Treatment given was $0.05 \%$ clobetasol propionate cream (Dermovat $^{R}$, Glaxo) and an emollient (Essex cream $^{R}$, Essex) in the following intermittent schedule. Clobetasol propionate cream was applied twice daily on days $1,2,3,4,8,9,12$ and 14 . The inert cream base was used on days $5,6,7,10,11$ and 13. The patients were seen after fourteen days and new samples were taken from the same sites as before treatment using the same technique.

Antibacterial effect of clobetasol propionate. The in vitro antibacterial effect of clobetasol propionate (2000, 1000, 500, 250, $125,62,31$ and $16 \mu \mathrm{g} / \mathrm{ml})$ on $\mathrm{S}$. aureus was investigated using the agar dilution technique in ASM-PDM agar (BiodisC AB, Stockholm, Sweden) using $10^{5} \mathrm{cfu}$ as inoculum.

Statistics. Geometric means of groups of bacteria were compared with paired $\underline{t}$-tests (112). A significance level of $5 \%$ was chosen. 


\section{RE S L L T}

Prevalence of individual risk factors. Of the total cohort studied we considered $22.6 \%$ to be atopics. A history of atopic dermatitis was seen in $10.2 \%$ including $4.1 \%$ with both atopic dermatitis and atopic mucosal symptoms. Pure atopic mucosal symptoms were found in $12.4 \%$. The prevalence figures for atopy were essentially the same in the four occupational groups. A history of metal dermatitis was reported by $26.3 \%$ of the women in wet hospital work and was more common in atopics than in non-atopics. The following relative frequency for HMD was found: AD 36.5\% $(p<0.001)$, AMS $31.4 \%(p<0.05)$ and NA 24.1\%. A hïstory of earlier hand eczema was reported by $22.4 \%$ of the women in wet hospital work. The following figures for earlier hand eczema were found: AD 48\%, AMS 24\%, NA $18 \%$, HMD $36 \%$ and subjects without HMD 17\%. A history of metal dermatitis was more common in atopics (46.9\%) and non-atopics (40.0\%) subjects with HHE than in atopics (26.7\%) and non-atopics $(20.5 \%)$ without HHE $(p<0.001)$.

Hand eczema in the four occupations. Hand eczema prior to the current work had occurred in $21.7 \%$ of the nursing staff, in $20.4 \%$ of the kitchen workers/cleaners, in $23.5 \%$ of the office workers and in $8.2 \%$ of the caretakers/craftsmen.

Table II shows the total occurrence of hand eczema in the four occupations during follow-up. The difference in hand eczema between wet and dry work is small and seems to diminish in the more severe forms of hand eczema. It is open to question whether 
Table II Hand eczema in occupational groups; median observation time: 20 months

\begin{tabular}{|c|c|c|c|c|}
\hline & $\begin{array}{l}\text { Nursing } \\
\text { staff }\end{array}$ & $\begin{array}{l}\text { Kitchen } \\
\text { workers/ } \\
\text { cleaners }\end{array}$ & $\begin{array}{l}\text { Office } \\
\text { workers }\end{array}$ & $\begin{array}{l}\text { Caretakers/ } \\
\text { craftsmen }\end{array}$ \\
\hline $\begin{array}{l}\text { Total number in the } \\
\text { group }(*)\end{array}$ & 1599 & 450 & 264 & 110 \\
\hline \multicolumn{5}{|l|}{ Hand eczema (\%) } \\
\hline - by questionnaire & 41 & 37 & 25 & 17 \\
\hline $\begin{array}{l}\text { - as cause of medical } \\
\text { consultation }\end{array}$ & 9.8 & 14 & 7.6 & 7.3 \\
\hline $\begin{array}{l}\text { - as cause of sick- } \\
\text { leave }\end{array}$ & 1.9 & 3.6 & 1.5 & 0 \\
\hline $\begin{array}{l}\text { - as cause of termina- } \\
\text { tion of current work }\end{array}$ & 2.0 & 2.4 & 0.4 & 0 \\
\hline
\end{tabular}

(*) A small deficit due to incomplete questionnaires.

the figures really reflect the importance of the current work as a causal factor for hand eczema, as 50\% had been working part-time and $1 / 3$ of the workers had left their jobs at the time of the follow-up. However, no significant difference in the occurrence of hand eczema was seen between full-time and part-time workers and only $5.8 \%$ of the employees with hand eczema reported that the eczema started after the cessation of work.

Hand eczema in atopics. Hand eczema prior to the current work had occurred in $52.5 \%$ of the subjects with atopic dermatitis, in $21.7 \%$ of the subjects with atopic mucosal symptoms and in $16.3 \%$ of the non-atopics. During the follow-up subjects with atopic dermatitis 


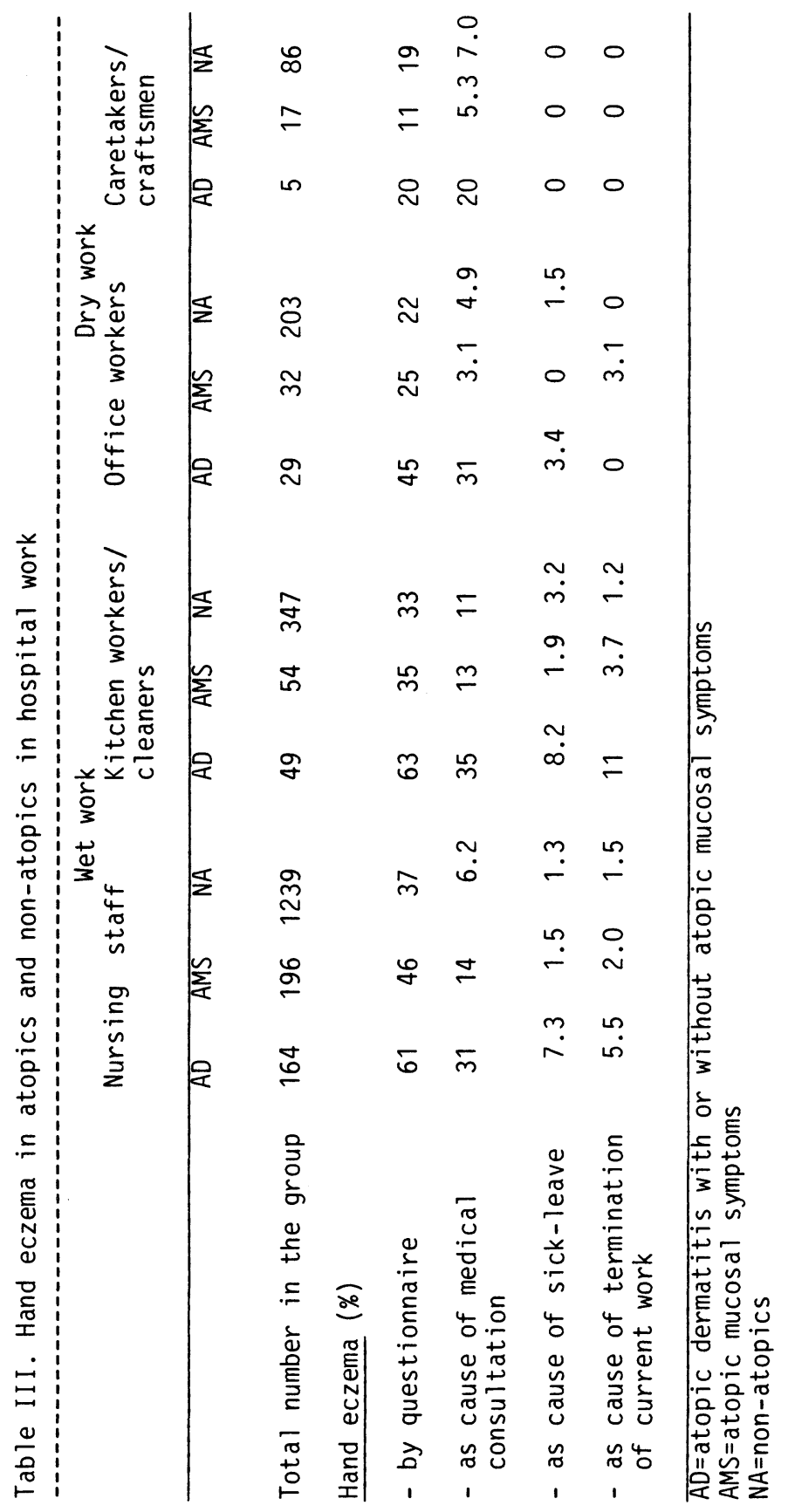


had higher frequencies of hand eczema than subjects with atopic mucosal symptoms and non-atopics (Table III). The difference between the groups increased in the more severe forms of hand eczema. Sick-leave because of hand eczema was fairly uncommon (0$3.4 \%$ ) in most occupations but for subjects with atopic dermatitis employed in wet work occupations, the figures were higher (7.3$8.2 \%)$. Of the subjects on sick-leave, $75 \%$ had been absent from work for less than one month. Most employees with hand eczema do not consult a doctor. The following reasons were given by 677 employees: the hand eczema was mild (69.0\%), the employee treated himself with various topical remedies (43.9\%), the eczema healed fast spontaneously (36.5\%) and other reasons (17.4\%).

Hand eczema in women in wet hospital work. Table IV gives the figures for the occurrence of hand eczema in women in wet hospital work. From the total figure it can be seen that hand eczema was reported by $41 \%$ and only $2.4 \%$ had been on sick-leave. $2.2 \%$ had left their current work because of hand eczema. Atopic dermatitis, metal dermatitis and earlier hand eczema increased the occurrence of hand dermatitis. Many subjects with hand eczema had suffered their first bout of eczema prior to the current wet work. The following figures for HHE in subjects with current hand eczema were found: AD $68 \%$, AMS $45 \%$, NA $42 \%$, HMD $55 \%$ and without HMD $42 \%$. Thus $46 \%$ of all subjects with current eczema had had hand eczema before the observation period. 


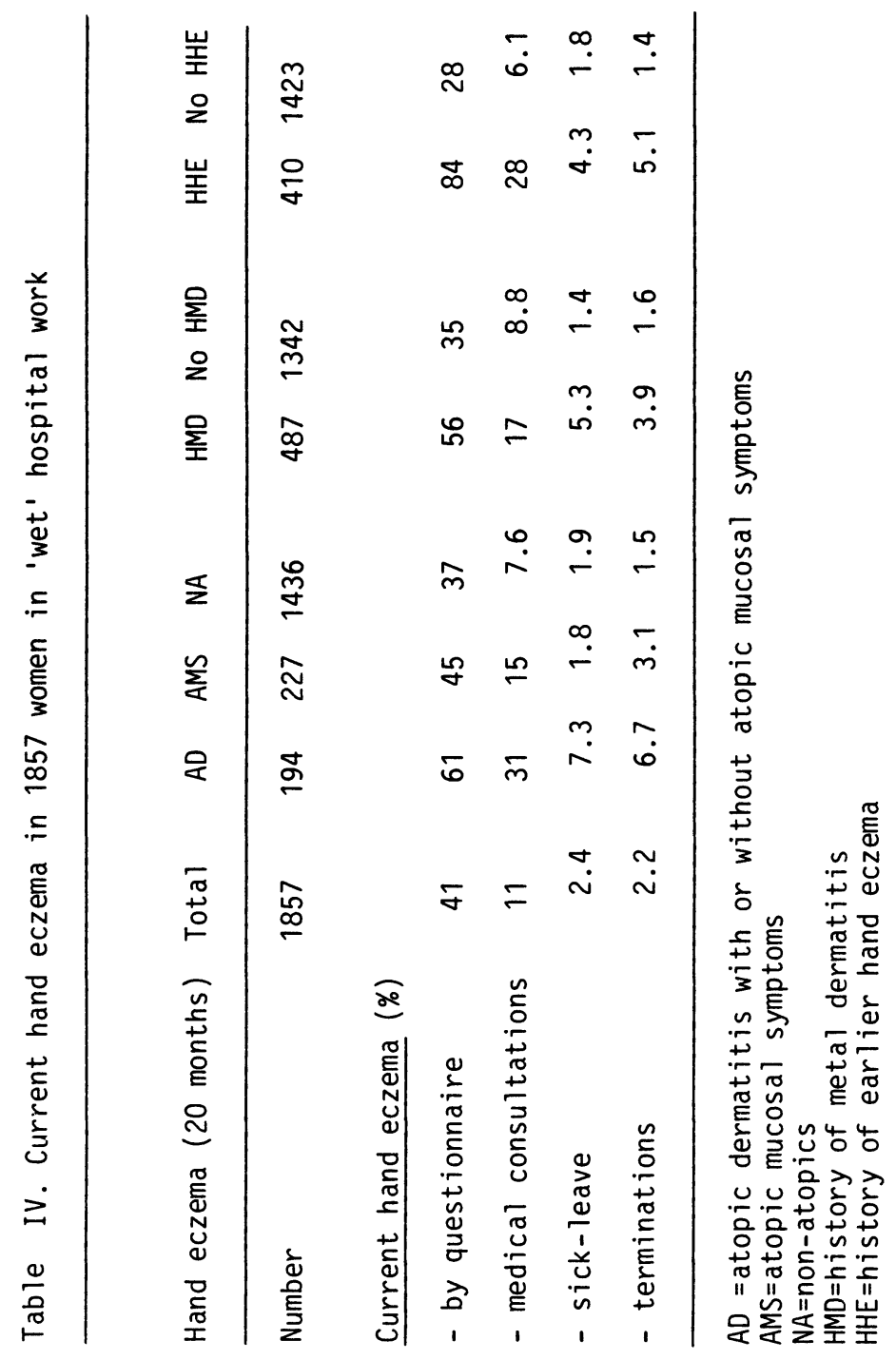




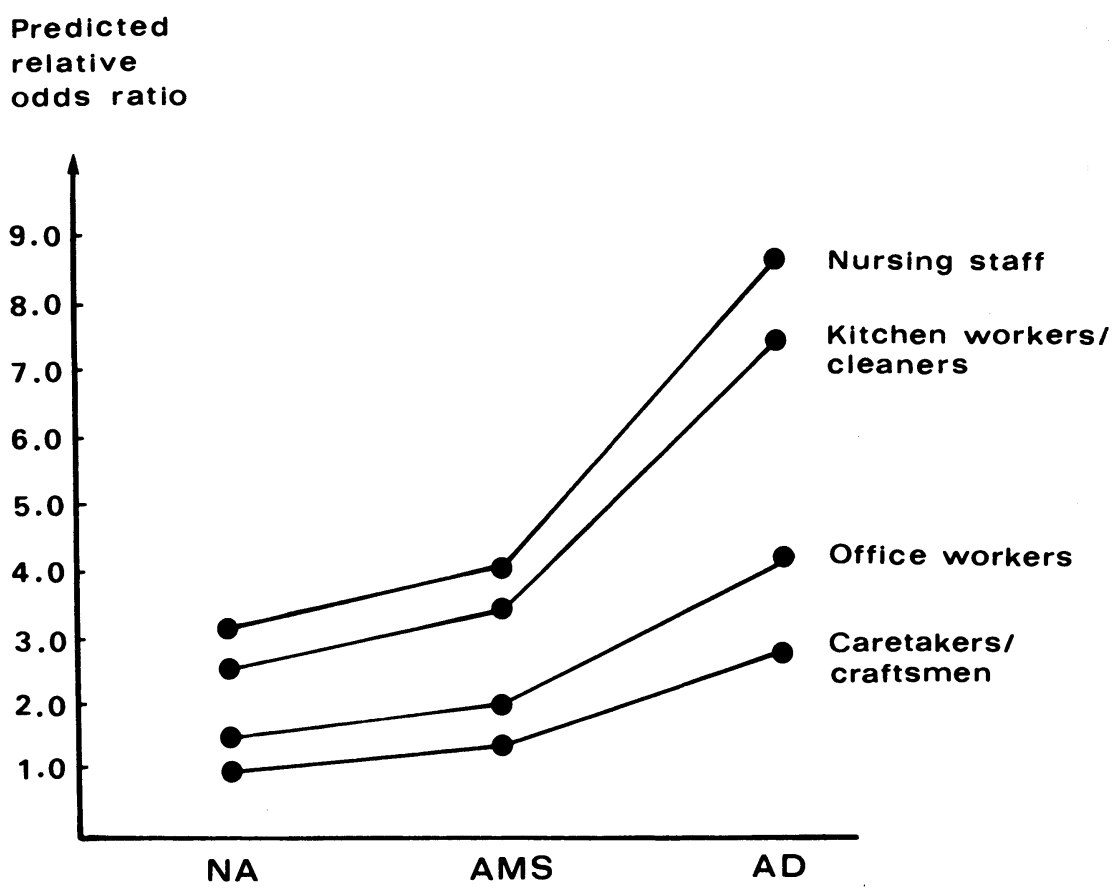

Figure 1. Predicted relative odds ratio for hand eczema in atopics and non-atopics in the occupational groups. NA, AMS and AD as defined in Table III.

Multivariate regression analysis of risk factors. In the regression analysis named $A 1$ the following factors were found to significantly influence the occurrence of hand eczema: atopic dermatitis $(F=54, p<0.0001)$, occupation $(F=14.4, p<0.0001)$. Figure 1 
shows a summarized schematic description of the predicted relative odds ratios of developing hand eczema for atopics and non-atopics in the four occupations. Subjects with atopic dermatitis showed odds approximately three times higher than non-atopics in both wet and dry work. Nursing staff showed odds approximately three times higher than caretakers/craftsmen and twice as high as office workers. The group termed caretakers/craftsmen was small and the prediction is therefore uncertain in this group. The predicted probability of hand eczema for this analysis ranges from $16 \%$ in non-atopic caretakers/craftsmen to $62 \%$ in nursing staff with atopic dermatitis (Table V).

Table V. Predicted relative odds ratios (OR) and predicted probability (PP) for hand eczema in the occupational groups

\begin{tabular}{|c|c|c|c|c|c|c|}
\hline & \multicolumn{2}{|c|}{ NA } & \multicolumn{2}{|c|}{ AMS } & \multicolumn{2}{|c|}{$A D$} \\
\hline & $\mathrm{OR}$ & PP & $\mathrm{OR}$ & PP & $\mathrm{OR}$ & $\mathrm{PP}$ \\
\hline & & $\%$ & & $\%$ & & $\%$ \\
\hline Nursing staff & 3.2 & 37 & 4.1 & 44 & 8.8 & 62 \\
\hline $\begin{array}{l}\text { Kitchen workers/ } \\
\text { cleaners }\end{array}$ & 2.7 & 33 & 3.5 & 39 & 7.5 & 58 \\
\hline Office workers & 1.5 & 22 & 2.0 & 27 & 4.2 & 44 \\
\hline $\begin{array}{l}\text { Caretakers / } \\
\text { craftsmen }\end{array}$ & 1.0 & 16 & 1.3 & 20 & 2.8 & 34 \\
\hline
\end{tabular}

$\overline{A D}$, AMS, NA as defined in Table III. 
In the regression analysis named $A 2$ the following factors significantly increased the occurrence of hand eczema: atopic dermatitis $(F=54, \quad p<0.001)$, occupation $(F=14.4, p<0.0001)$, children younger than four years old $(F=13.9, p<0.001)$ and lack of dish-washing machine $(F=8.6, p<0.05)$. From the population in this analysis $16.4 \%$ had children younger than 4 years old and $70.4 \%$ had no dishwashing machine. Figure 2 shows the odds ratios for hand eczema in atopics and non-atopics in the different occupations when consideration was taken of the importance of the significant domestic parameters. The predicted odds for the most favourable and the most unfavourable combinations of the two significant domestic parameters in the occupations have been outlined. The odds for hand eczema in an occupation is twice as high for subjects with the most unfavourable combination of domestic factors as for subjects with the most favourable combination. Office workers with an unfavourable combination of domestic parameters show as great a risk of developing hand eczema as wet workers with a favourable combination of home factors. Wet work in combination with unfavourable domestic factors increased the odds by four times compared to dry work and a favourable combination of domestic factors. The predicted probability of hand eczema for this analys is ranges from $18 \%$ in non-atopic office workers with the most favourable combination of domestic factors to $72 \%$ in nursing staff with atopic dermatitis and the most unfavourable combination of domestic factors (Table VI). 


\section{Predicted \\ relative}

odds ratio

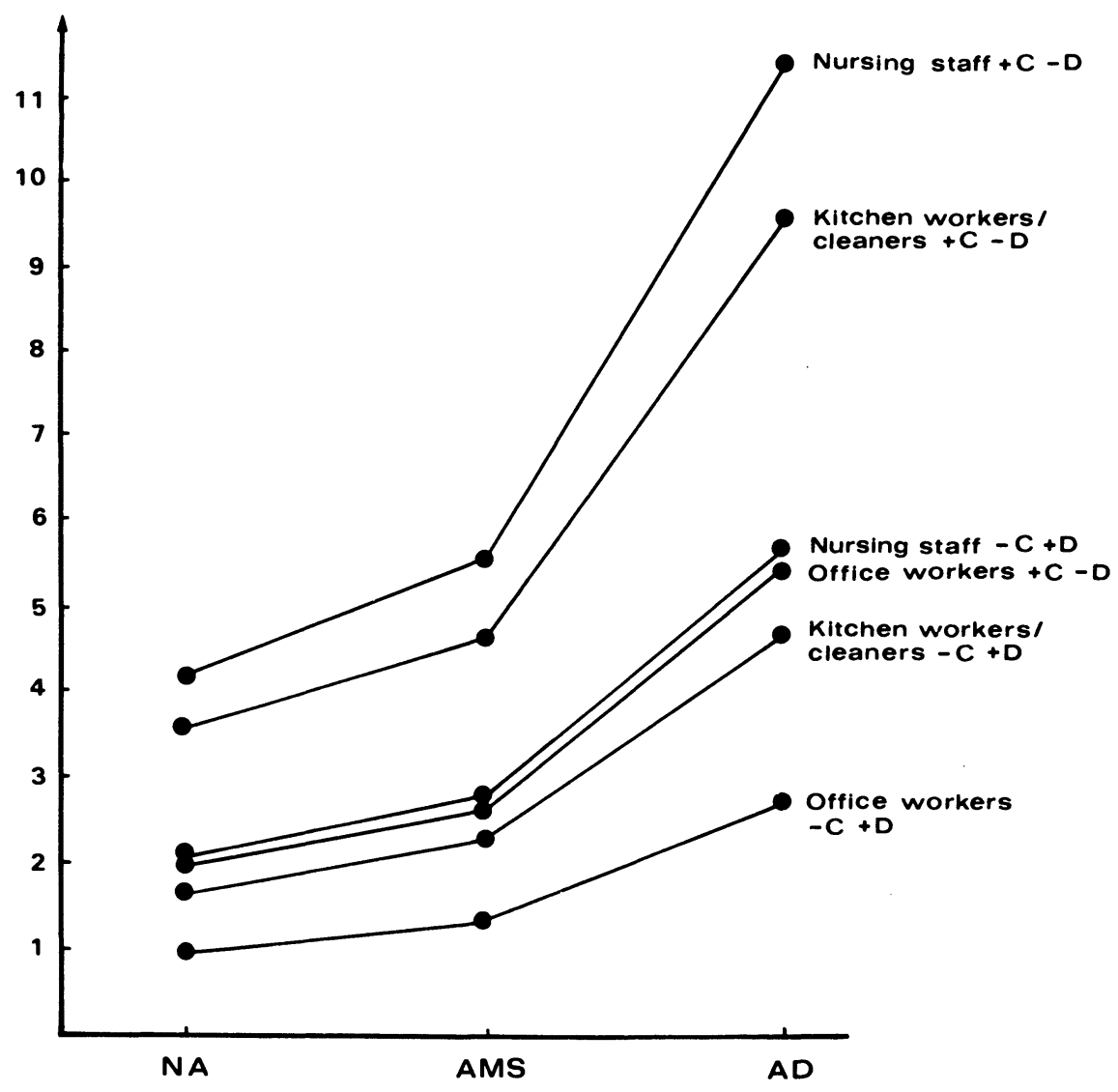

$+C=\quad$ children $<4$ yrs old

- C = no " " " "

$+D=$ dish-washing machine

- $D=$ no .

Figure 2. Predicted relative odds ratios for hand eczema in atopics with the most favourable and unfavourable combinations of domestic work. NA, AMS and AD as defined in Table III. 
Table VI. Predicted odds ratios (OR) and predicted probability (PP) for hand eczema in atopics and non-atopics with the most favourable and unfavourable combinations of significant domestic factors.

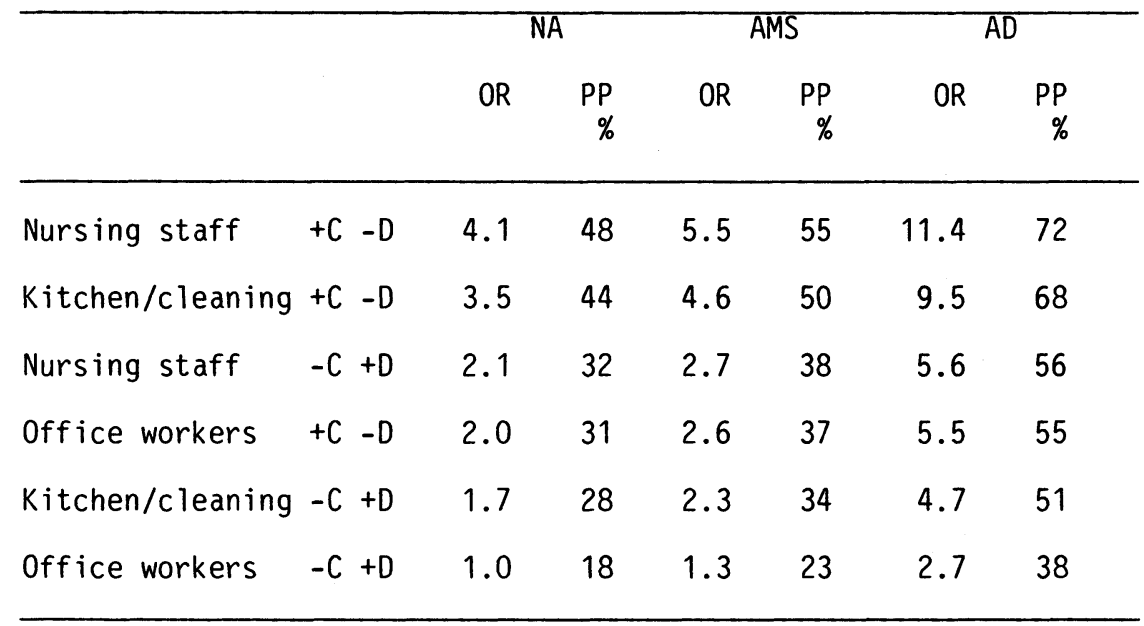

$+C=$ children $<4$ years old

$-C=$ no children $<4$ years old

$+D=$ dish-washing machine

$-D=$ no dish-washing machine

In the regression analysis called $A 3$ the following factors were found to influence the occurrence of hand eczema: history of earlier hand eczema $(F=540, p<0.0001)$, history of metal dermatitis $(F=68, \quad p<0.001)$ and atopic dermatitis $(F=38, p<0.001)$. Figure 3 shows the interrelation of HHE, HMD and atopy in a summarized schematic description of the predicted relative odds ratios of hand eczema. HHE increased the odds by 12.9 times and created a subdivision of the population into two groups which differ considerably as regards risk of developing hand dermatitis. HMD further increased the odds by 1.8 times and AD and AMS by another 1.3 times. The predicted probability of hand eczema in this analy-
$A D$, AMS, NA as defined in Table III. 
sis ranges from $24 \%$ in non-atopic subjects without HMD and without HHE to $91 \%$ in subjects with $A D, H M D$ and HHE (Table VII).

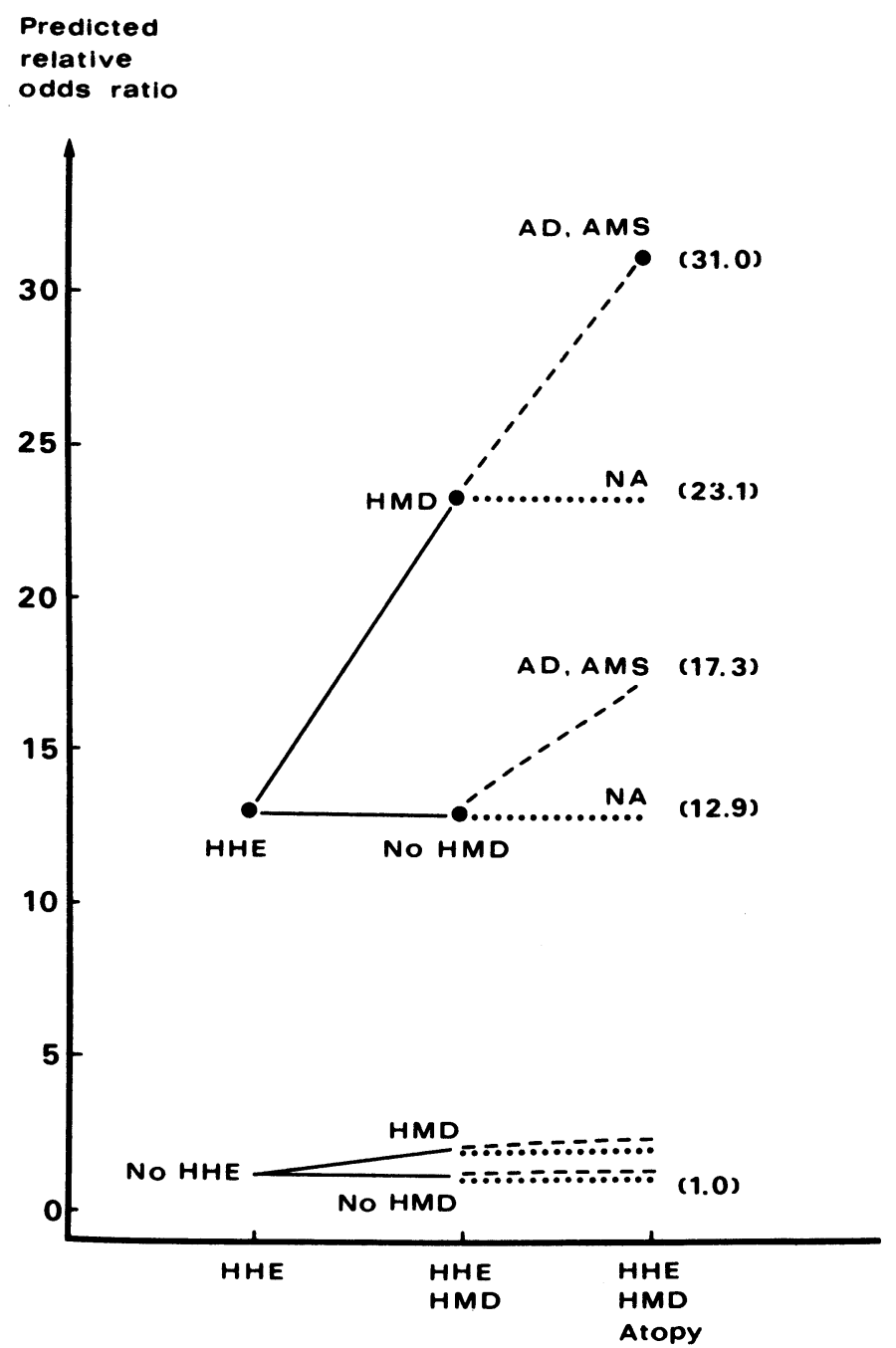

Figure 3. Relative odds ratios for hand eczema in the various groups during 20 months of 'wet' hospital work. HHE=history of hand dermatitis; $A D$, AMS, NA as in Table III; HHE, HMD as in Table IV. 
Table VII. Predicted relative odds ratios (OR) and predicted probability (PP) for hand eczema and its consequences in women in wet work.

\begin{tabular}{|c|c|c|c|c|c|}
\hline & \multicolumn{2}{|c|}{ Hand eczema } & \multirow{2}{*}{$\begin{array}{l}\text { Medical } \\
\text { consultation } \\
\text { PP\% }\end{array}$} & \multirow{2}{*}{$\begin{array}{c}\text { Sick-leave } \\
\text { PP\% }\end{array}$} & \multirow{2}{*}{$\begin{array}{l}\text { Changed } \\
\text { work } \\
\text { PP\% }\end{array}$} \\
\hline & $\mathrm{OR}$ & $\mathrm{PP} \%$ & & & \\
\hline$A D$ & 31 & 91 & 57 & 14 & 14 \\
\hline & 31 & 91 & 42 & 5.6 & 9.1 \\
\hline$H M D-N A$ & 23.1 & 88 & 28 & 5.6 & 5.5 \\
\hline$A D$ & 17.3 & 84 & 53 & 6.6 & 10 \\
\hline & 17.3 & 84 & 37 & 2.6 & 6.5 \\
\hline HHE - No HMD- NA & 12.9 & 80 & 25 & 2.6 & 3.9 \\
\hline$A D$ & 2.4 & 43 & 48 & 22 & 14 \\
\hline & 2.4 & 43 & 34 & 9.5 & 9.1 \\
\hline HMD- NA & 1.8 & 36 & 22 & 9.5 & 5.5 \\
\hline$A D$ & 1.3 & 30 & 44 & 11 & 10 \\
\hline & 1.3 & 30 & 30 & 4.3 & 6.5 \\
\hline No HHE-NO HMD-NA & 1.0 & 24 & 19 & 4.3 & 3.9 \\
\hline
\end{tabular}

Medical consultation: $A D p<0.001$, HHE $p<0.01$

Sick-leave: $A D \mathrm{p}<0.01$, HMD $\mathrm{p}<0.05$

Changed work: $A D p<0.01$

Severity of hand eczema. The consequences of the current hand eczema in women in wet work as regards medical consultation, sickleave and termination of work due to hand eczema were analyzed statistically. It was found that $A D(F=35.4, p<0.001)$ and HHE $(F=9.4, p<0.01)$ increased the need for medical consultation. Atopic dermatitis $(F=6.7, p<0.01)$ and HMD $(F=6.1, p<0.05)$ in- 
creased sick-leave and $A D \quad(F=7.3, p<0.01)$ increased the terminations due to hand eczema. The predicted probability of medical consultation, sick-leave and termination were found within the following ranges: medical consultation 19-57\%, sick-leave $2.6-22 \%$, termination $3.9-14 \%$ (figures as a percentage of the total number for current hand eczema). Figures for medical consultation, sickleave and termination in the various groups are given in Table VII. Table VIII shows that vesicular lesions, permanent symptoms and onset within four months were significantly more common in subjects with atopic dermatitis. 'Dry and chapped skin with rashes and small cracks' was recorded as the only symptom of the current hand eczema in $24 \%$ of subjects with atopic dermatitis, in $43 \%$ of subjects with atopic mucosal symptoms ( $p<0.01$ vs $A D)$ and in $46 \%$ of the non-atopics $(p<0.01$ vs $A D)$.

Table VIII. Severity of hand eczema

AD AMS NA

Number of employees with hand eczema

145

Vesicular lesions

Permanent symptoms

Onset of hand eczema within the first 4 months of occupation
$119 \quad 634$

$\begin{array}{ccc}\% & \% & \% \\ 44 & 22^{\star \star} & 22^{\star \star \star} \\ 20 & 10^{\star} & 6.1^{\star \star \star} \\ 76 & 59^{\star \star} & 54^{\star \star \star}\end{array}$

*) $p<0.05$, versus $A D ; \star \star *) ~ p<0.01$, versus $A D ; \star \star \star *) p<0.001$, versus $A D$ 
Investigated patients (III). Past or present atopic dermatitis with or without mucosal symptoms was found in $46 \%$ of the subjects. Atopic mucosal symptoms without a history of atopic dermatitis were seen in $12 \%$ and $42 \%$ were considered non-atopics. A history of metal dermatitis appeared in $41 \%$.

Earlier hand eczema in investigated patients. Hand eczema prior to current employment occurred in $66.7 \%$ of the subjects. No difference was found between atopics and non-atopics in the occurrence of previous hand eczema. The time lapse since the onset of earlier hand eczema ranged from 4 months to 30 years (mean 5 years). The periodicity of earlier hand eczema was characterized as once or twice in $7.5 \%$, sometimes in $52.5 \%$, often in $39.8 \%$ and permanently in none. Occupation at the time of onset of the earlier eczema was given as wet work by $40.1 \%$, industrial work by $4.2 \%$ and dry work by $16.2 \%$, while $39.4 \%$ did not connect the onset of hand eczema with any occupation.

Current hand eczema in investigated patients. The current hand eczema was considered by $92.3 \%$ of the employees to be elicited by external contacts. Water, cleaning agents, physical factors, disinfectants, food stuffs and the wearing of gloves were the most commonly reported causes. Contact with eliciting factors was considered to take place mostly at work by $57.2 \%$, equally at work and at home by $21 \%$ and mostly at home or in leisure time by $13.8 \%$ of the patients. A history of contact urticaria was reported by $49 / 142(34.5 \%)$ and was more common after exposure to substances in the home. Various kinds of food, cleaning agents and animals were 
most commonly considered to provoke contact urticaria at home and in leisure time. The agents most commonly reported at work were cleaning agents, vegetables and rubber gloves.

State of current hand eczema. At the time of the investigation, $100 / 142$ patients had eczema of the hands. Recent hand dermatitis, without clinical signs of ongoing eczema except for minor erythema and dry or chapped skin, was seen in $42 / 142$ patients. The following sites of the current hand eczema were noted: interdigital and dorsal aspects of the fingers $82 \%$, palms of fingers $32 \%$, dorsa of hands $41 \%$, palms of hands $28 \%$ and finger-tips $15 \%$. Vesicles were present in $43 \%$, erosions and/or crusts in $33 \%$ and 1 ichenifications in $11 \%$. The lesions itched in $61 \%$ of the patients with ongoing hand eczema.

The clinical picture was described as a red vesicular scaly eczema in $93 \%$, finger-tip eczema in $6 \%$ and neurodermitis in $1 \%$. Ongoing eczema at sites other than the hands was seen in $35 / 142$ (24.6\%). Atopic eczema was present in 23 , metal dermatitis in 4 , seborrhoic eczema in 3, neurodermitis in 2, ichthyosis with eczema in 1, external otitis in 1 and nummular eczema in 1 patient. From these figures, it is obvious that approximately $1 / 3$ of the patients with atopic dermatitis and hand eczema had manifestations at other sites.

The exogenous causes of current hand eczema were judged to be mostly (>50\%) of occupational origin in $72 \%$. of the subjects investigated, $14.8 \%$ were on sick-leave for some period because of current hand eczema. 
Contact allergy. Delayed contact sensitivity was found in 45 of the 120 patients tested. There were 71 positive tests, of which 54 were relevant. The allergens are listed in order of decreasing frequency in Table IX. Of the patients tested, 68 were atopics and 52 non-atopics. No significant difference between them was seen in the total number of positive tests or in reactions to nickel. Nickel and/or cobalt allergy was found in 25 of the 45 patients with contact allergy. Of all the women tested $83 \%$ had had their ears pierced. Contact allergy to nickel was found in 18/88 (20.5\%) of those with pierced ears and in $1 / 18(5.6 \%)$ of those without pierced ears. The difference is significant $(p<0.05)$.

Table IX. Positive patch test reactions in 120 patients

$\%$

$\begin{array}{lr}\text { nickel } & 18.2 \\ \text { cobalt } & 7.4 \\ \text { balsam of Peru } & 5.8 \\ \text { carba mix } & 4.1 \\ \text { formaldehyde } & 4.1 \\ \text { benzalkonium chloride } & 4.1 \\ \text { PPD mix } & 3.3 \\ \text { wood tars } & 3.3 \\ \text { thiuram mix } & 2.5 \\ \text { caine mix } & 1.8_{\star} \\ \text { fragrance mix } & 1.8 \\ \text { colophony } & 1.7 \\ \text { chromium } & 1.7 \\ \text { P-phenylenediamine } & 0.8\end{array}$

‡) As a \% of 55 patients tested.

A history of metal dermatitis was found in $33 / 68(48.5 \%)$ of the atopics and $18 / 52(34.6 \%)$ of non-atopics, the difference not being significant. Of 51 patients with a history of metal dermatitis, a 
positive patch test to nickel and/or cobalt was obtained in only $19 / 51$ (37.3\%). The corresponding figure for atopics was $12 / 33$ (36.4\%) and for non-atopics $7 / 18$ (38.9\%). Among subjects with no history of metal dermatitis, a positive test to nickel and/or cobalt was found in $4 / 35(11.4 \%)$ of the atopics and $2 / 34(5.9 \%)$ of the non-atopics.

In only 2 out of 10 patients allergic to rubber chemicals was there a clear correlation between occupational exposure to rubber gloves and the current hand eczema.

Many patients suspected that they had contact allergy prior to patch testing and had tried to avoid the allergens. Although minor exposure of the hands to the different allergens was common, few patients thought that contact allergy played any significant role as a cause of the current episode of hand eczema.

Contact urticaria. Tables $X$ and $X I(113-135)$ show the figures and relevance for positive prick tests. Substances which occur in the agents tested and known from the literature to elicit contact urticaria have been listed in the tables. One or more positive prick test reactions were seen in 32 out of 41 patients tested. In 22, the positive test(s) was relevant. The total number of positives was 68 and the relevance to contact urticaria on normal or dermatitic skin was $32 / 68$. 


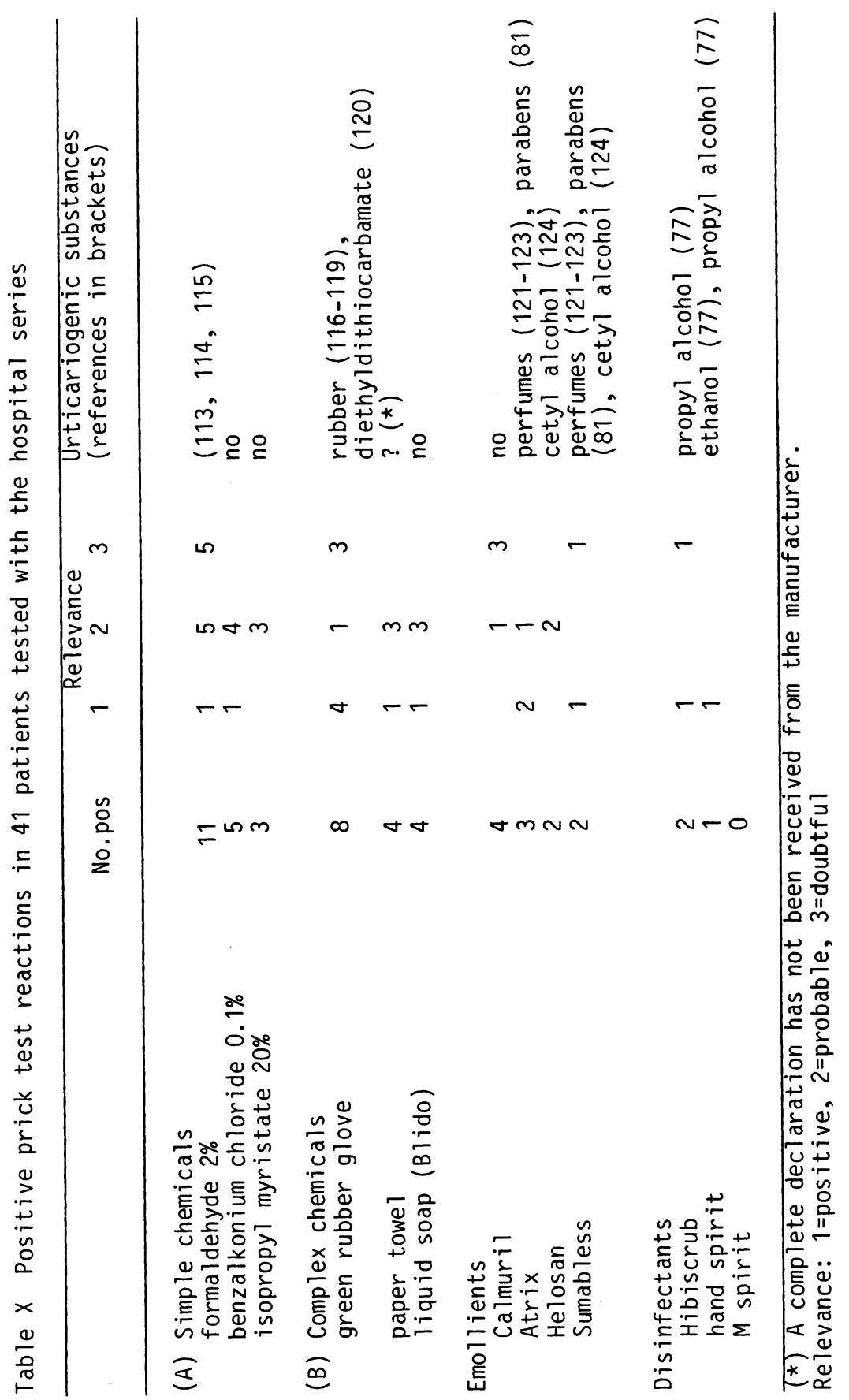




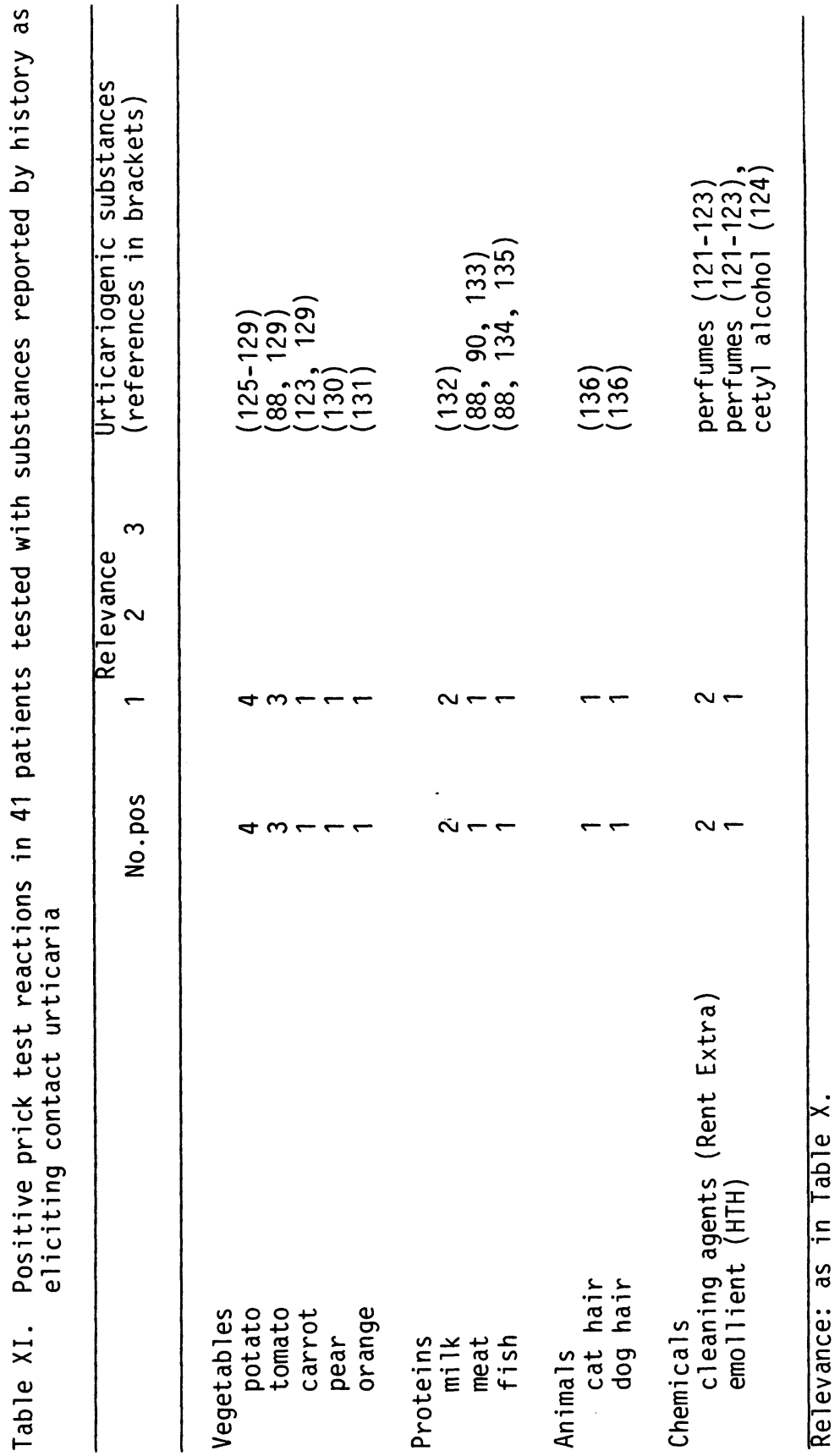


In 24 atopics a total of 46 positive prick tests was seen, and in 17 non-atopics 22. Although the figure in the atopics was higher, the difference is not significant.

Most patients with relevant contact urticaria were aware of it prior to testing, and if possible they avoided the substances responsible. Some with a positive test for the complex chemicals in the hospital screening series remembered a history of immediate reaction on the hands especially on dermatitic skin. In a small number of patients, predominantly those who reacted to rubber and disinfectants, immediate urticarial reaction caused real problems because of the difficulty of avoidance. In two patients, prick tests were positive to both benzalconium chloride and the emollient Helosan which contains it.

Morphology of hand eczema in the bacteriological study (IV). The eczematous lesions sampled showed the following morphology before treatment: erythema with papules and/or infiltration was noted in $20 / 20$, vesicles in $16 / 20$, erosions, fissures and crusts were seen alone or in combination in 14/20, signs of clinical infections with exsudation and yellow crusts were seen in 3/20. Because of the localization of the eczematous lesions a majority (43/56) of all samples taken at the first visit were from fingers and only $13 / 56$ from other parts of the hands. The extent of the eczematous lesions was estimated as small in 4/20, medium in $14 / 20$ and large in 2/20 patients. Nine of the patients were on sick-leave during treatment. At follow-up the eczematous lesions were suppressed and the skin was essentially normal-looking in $18 / 20$ patients and in the other 2/20 patients the eczema was much improved. 
Table XII. Frequency of isolated bacteria before and after topical treatment with clobetasol propionate

\begin{tabular}{lccc}
\hline Bacteria & $\begin{array}{c}\text { Eczema } \\
n=20\end{array}$ & $\begin{array}{l}\text { Erythema } \\
n=16\end{array}$ & $\begin{array}{l}\text { Normal skin } \\
n=20\end{array}$ \\
Before After & Before After & Before After \\
\hline
\end{tabular}

\section{Aerobes}

$\begin{array}{llllllll}\text { Staphylococcus aureus } & 18 & 6 & 13 & 4 & 8 & 2\end{array}$

S. epidermidis

68

13

63

S. warnerii

10

2

3

3

S. cohnii

S. capitis

$0 \quad 0$

20

10

S. hominis

S. hemolyticus

S. saprophyticus

$0 \quad 0$

10

0

0

Micrococcus species

Corynebacteria ${ }^{1)}$

Corynebacteria ${ }^{2)}$

Coliform bacteria

12

11

2

0

30

10

21

$\begin{array}{llll}0 & 1 & 0 & 0 \\ 0 & 0 & 0 & 0\end{array}$

$\begin{array}{ll}1 & 0 \\ 3 & 2\end{array}$

10

13

0

3

0

2

41

$\begin{array}{llllll}1 & 2 & 1 & 0 & 1 & 1 \\ 1 & 0 & 1 & 0 & 0 & 0\end{array}$

\section{Anaerobes}

Propionibacteria

10

0

0

\section{Peptostreptococci}
1) lipophilic
2) non-lipophilic
3) all isolates from the non-atopic group of patients
4) after treatment skin was normal-looking in 18/20 patients 
Microbial flora and effect of treatment. The incidence of the isolated organisms is shown in Table XII. Before treatment the

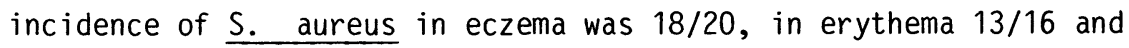
in normal skin 8/20. Treatment with clobetasol propionate reduced

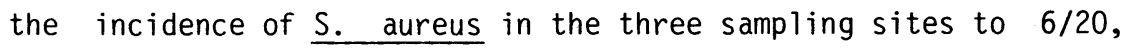
$4 / 16$ and 2/20 respectively.

Table XIII. Bacterial counts expressed as colony forming units (CFU) before and after topical treatment with clobetasol propionate

Staphylococcus Other aerobes Anaerobes aureus

$$
\mathrm{CFU} / \mathrm{cm}^{2} \quad \mathrm{CFU} / \mathrm{cm}^{2} \quad \mathrm{CFU} / \mathrm{cm}^{2}
$$

$\begin{array}{lllll}\text { Normal skin } & \text { Before } & 1.7^{\star} \pm 0.9 & 2.1 \pm 0.9 & 1.9 \pm 1.1 \\ n=20 & \text { After } & 1.1 \pm 0.3 & 1.9 \pm 0.7 & 1.9 \pm 0.8\end{array}$

$\begin{array}{lllll}\text { Erythema } & \text { Before } & 3.4 \pm 1.4 & 2.5 \pm 0.9 & 2.2 \pm 1.1 \\ \mathrm{n}=16 & \text { After } & 1.3 \pm 0.6 & 2.1 \pm 0.7 & 2.2 \pm 1.0\end{array}$

$\begin{array}{lllll}\text { Eczema } & \text { Before } & 4.8 \pm 1.5 & 2.4 \pm 1.2 & 1.9 \pm 1.4 \\ n=20 & \text { After }^{\star \star} & 1.3 \pm 0.6 & 2.4 \pm 0.8 & 1.9 \pm 1.0\end{array}$


The bacterial geometric mean counts $/ \mathrm{cm}^{2}$ before and after treatment are shown in Table XIII. The mean density before treatment of $\underline{S}$. aureus in eczema was $56000 \mathrm{cfu} / \mathrm{cm}^{2}$, in erythema $2600 \mathrm{cfu} / \mathrm{cm}^{2}$ and in normal skin $45 \mathrm{cfu} / \mathrm{cm}^{2}$. The mean count of $\underline{\mathrm{s} \text {. aureus in }}$ the three sites differs significantly $(p<0.01)$. Treatment reduced the counts of $\underline{S}$. aureus in the three sampling sites significantly: in earlier eczema to $22 \mathrm{cfu} / \mathrm{cm}^{2}(\mathrm{p}<0.001)$, in previous erythema to $21 \mathrm{cfu} / \mathrm{cm}^{2}(p<0.001)$ and in normal skin to $13 \mathrm{cfu} / \mathrm{cm}^{2} \quad(p<0.05)$. The occurrence of other aerobes or anaerobes did not differ significantly in the three sampling sites before treatment. Nor was there a significant reduction in the geometric mean count of these bacterial groups in the three sites after treatment.

Before treatment S. aureus constituted $89 \%$ of the total aerobic flora in eczema, $73 \%$ in erythema and $41 \%$ in normal skin. After treatment $S$. aureus constituted $21 \%$ of the total aerobic flora in eczema, $22 \%$ in erythema and $24 \%$ in normal skin. Before treatment S. aureus was found in densities exceeding $10^{5} \mathrm{cfu} / \mathrm{cm}^{2}$ in the eczematous lesions of 15 patients. Only 1 patient had more than $10^{6} \mathrm{cfu} / \mathrm{cm}^{2}$. The three patients with clinical signs of infection had the following counts for $S$. aureus: $3.0 \times 10^{5}, 3.2 \times 10^{5}$ and $2.3 \times 10^{6} \mathrm{cfu} / \mathrm{cm}^{2}$. The two patients who did not carry $\mathrm{S}$. aureus in their eczematous lesions were non-atopics. The mean count for $\underline{S}$. aureus in the atopics did not differ significantly from the counts that were found in the non-atopics. 
Fifty freshly isolated clinical strains of $\underline{S}$. aureus were tested for the antibacterial effect of clobetasol propionate in vitro. No inhibitory effect of the substance was demonstrated in the dose range tested. 


\section{I S C U S S I O N}

The cohort and patients studied. The cohort in this study was dominated by young women newly employed in four Swedish hospitals. Therefore the conclusions may be considered relevant only for similar individuals in similar working conditions. However, as the individual factors were found to be most important in the etiology of hand eczema, the main findings are probably significant for young women in the general population.

The patients with hand eczema who were clinically investigated are not representative of the general population. These patients represent the top of the epidemiologic iceberg of hand eczema and risk individuals are overrepresented. This indicates that it is not possible to draw uncritical conclusions of the nature of hand eczema in the population from a selected group of patients.

This study shows that most eczemas are mild, periodic, often selflimiting and in many cases they can be dealt with by self-treatment measures.

The patients with hand eczema in the bacteriological study were consecutive out-patients in a dermatologic department and were not selected except according to the exclusion criteria and the acceptance requirements for participation in this particular study.

Methodological aspects. The prospective cohort study design used in this investigation has many advantages over retrospective 
epidemiologic studies. The design makes it possible to quantitate and compare the relative importance of individual and environmental factors. Furthermore it is possible to follow the first period of employment in a risk occupation. It must be assumed that this period provides the most suitable opportunity for revealing individual differences as regards the risk of developing hand eczema. Various measures with the passage of time will probably equalize the differences between the groups. Thus patients with hand eczema will reduce irritant exposure, use emollients or topical cortico-steroids and high risk individuals especially will change their work and get lost in retrospective studies.

Follow-up in the cohort study was done by questionnaire. The final questionnaire was designed after a pilot-study on 400 employees using a test questionnaire. The total response rate to the followup questionnaire was acceptable and the partial drop-out rate for the various questions was limited to a few percent.

It was not possible to study the prevalence of hand eczema by means of clinical examination of each episode of eczema for the whole cohort over a period of 20 months. Therefore, we had to rely on anamnestic information about hand eczema given in the follow-up questionnaire. The combination of information about the symptomatology of hand eczema given before employment followed by a questionnaire was found to be a reliable way of diagnosing hand eczema. 
Atopy has been diagnosed exclusively by case history. This imposes limitations, but it is simple and practically useful in a large epidemiological study. As no absolute diagnostic criteria for atopic disease exist we have accepted this compromise.

Prevalence of hand eczema. The prevalence of hand eczema in women prior to their current employment in wet work was $22.4 \%$ which corresponds to the figure found in a study of a randomized sample of Danish women (5). Thus any selection of the studied cohort regarding previous hand eczema is unlikely.

The prevalence of hand eczema amongst those engaged in wet hospital work in this study is similar to the one found by Lammintausta (6). Lower prevalence figures have been found in other studies $(47,137,138)$. The possible reasons for these discrepances have been given earlier. The low figure for the occurrence of hand eczema in occupations dominated by men verifies previous findings of the sex difference $(1-4)$.

Prevalence of atopy and metal dermatitis. The prevalence figures for atopy obtained in our study are somewhat higher than the $15.1 \%$ found by Kjellman (11) in a study where he questioned 7-year-old children in Sweden. Several investigations exist and varying figures for atopy have been found (6).

The high figure for metal dermatitis may be explained by the fact that the cohort consists predominantly of young women with common exposure to metals. 
Individual risk factors for hand eczema. When atopic dermatitis was used as a risk factor for developing hand eczema without considering either previous hand eczema or metal dermatitis it was found to increase the odds approximately three times. This increase was seen in wet as well as in dry work. The figures for hand eczema among wet work employees with atopic dermatitis are similar to those found in a previous study (6).

The regression analysis on women in wet work clearly demonstrated the great importance of information about earlier hand eczema and metal dermatitis. It is obvious that many individuals with earlier hand eczema will suffer from recurrency if they are engaged in wet work. These high risk individuals constitute approximately half of the subjects with $A D$, one quarter of the subjects with AMS and one fifth of the non-atopics.

One possible explanation for the great importance of earlier hand eczema is that there is an endogenous characteristic of the skin, a skin vulnerability factor, which predisposes the person to develop irritant hand dermatitis. As the population consists of women, it may be assumed that they have been exposed to some degree of irritant occupational and domestic work in the past which sometimes, but not always, may have caused hand eczema. Thus earlier hand eczema may be considered a major indicator of this endogenous factor, which may correspond to the 'atopic skin diathesis' as defined by Lammintausta. This assumption is supported by Lammintausta who identified 'atopic skin diathesis' in $1 / 3$ of the subjects with AMS and in 19\% of the non-atopics. Atopic skin 
diathesis involved a significantly increased risk of developing hand eczema. No identification of this atopic skin diathesis was made in subjects with atopic dermatitis. It was, however, found in both Lammintausta's and Rystedt's studies that a considerable number of employees with atopic dermatitis had managed to work in wet occupations without developing hand eczema. In the present study $39 \%$ of the subjects with $A D$ reported no occurrence of hand eczema and these were predominantly subjects without earlier hand dermatitis.

The importance of endogenous factors in the etiology of hand eczema in subjects with atopic dermatitis is underlined in a study by Rystedt (9). In a report by Forsbeck et al. (28) it was found that $50 \%$ of the subjects with $A D$ and current eczema had their first bout of eczema prior to their first employment. In another retrospective study on occupational-dermatosis it was found that the relative odds of developing occupational skin diseases were calculated to be 13.5 times higher in atopics than in non-atopics (139)

There are other possible explanations for the great importance of a history of hand eczema. For example hand eczema in the past may leave a non-restored skin barrier for a long time and thus increase the risk of recurrency $(140,141)$.

A correlation between hand eczema and a history of metal dermatitis could be found on two levels in this study. At both levels 
HMD increased the odds by 1.8 times. According to the hypothes is presented high-risk subjects are those with HMD and an inherited disposition to irritant hand eczema occurring predominantly in atopics. This hypothesis is supported by a finding by Peltonen (142) that almost all nickel sensitive females afflicted with hand eczema were atopics. Further support is provided by the finding that hand dermatitis in nickel sensitive females seems to follow one of two causes: mild and transient or chronic and disabling (143). In addition it was reported that atopy made the prognosis for hand eczema worse in nickel sensitive women.

Severity of hand eczema. Most hand eczemas were mild with periodic symptoms and the employee could handle the disorder using selftreatment methods. Most subjects with hand eczema also managed to work during the observation period and the figures for sick-leave were very low in most groups thus confirming previous findings that most hand eczemas are mild (6).

Subjects with atopic dermatitis developed a more severe hand eczema than subjects with atopic mucosal symptoms and non-atopics. This difference in severity was not observed by Lammintausta perhaps because her study was retrospective and subjects with atopic dermatitis who get severe hand eczema early on in their careers might have left their jobs and thus have been lost to the study.

Occupational and domestic factors in hand eczema. Wet work only doubled the odds of developing hand eczema over dry office work. 
This difference between a high risk and a low risk occupation is unexpectedly small. One explanation may be that the population consists of women and it must be assumed that they are exposed to a considerable amount of irritant domestic work. Two anamnestically available parameters of domestic work namely 'nursing of children younger than 4 years old' and 'no dish-washing machine' were found to correlate significantly with the occurrence of hand eczema, probably because they increased the irritant load to above the average level. These findings verified the clinical experience that the nursing of small children of ten gives rise to hand eczema amongst women. Furthermore it seems justified to recommend the use of dish-washing machines to people suffering from hand eczema.

The relative importance of wet work may be greater in patients with a vulnerable skin factor. This assumption could not be documented in the present study as no comparison was possible between wet and dry work regarding previous hand eczema and metal dermatitis. However, the clinical investigation of the women in wet work with hand eczema supports this assumption as most of these high risk individuals claimed that their hand eczema had been elicited by trivial irritants.

Contact allergy and hand eczema. The patients with hand eczema who were patch tested had been exposed to the current wet work for 20 months at the most. Thus it must be assumed that sensitization in most patients with contact allergy must have occurred prior to the current work. This assumption is supported by the finding that 
no sensitization occurred in connection with the specially designed hospital patch test series. Although sensitization has occurred earlier, hand eczema may recur after occupational or domestic exposure to relevant allergens. Nevertheless, most employees with contact allergy could not correlate the current episode of hand eczema to any obvious exposure to the allergen. It must however be emphasized that allergens such as nickel and balsam of Peru are very common in the environment and some exposure of the hands is inevitable. Delayed contact sensitivity was seen in $38 \%$ of the patients tested. In another study of hospital workers, a positive patch test was found in $38 \%$ of the patients who had consulted an occupational doctor, and in $26 \%$ of all patients tested who had earlier or current hand dermatitis (6). The frequency of contact allergy to individual allergens was essentially similar to that of a previous study of hospital wet workers with hand dermatitis (6). One probable reason for the high figure for nickel allergy is that the patients were predominantly young women, a large number of whom had pierced their ears, which greatly increases the risk of nickel allergy (144, 145). These findings were verified in the present study.

Contact allergy to metals in subjects with metal dermatitis Contact allergy to nickel and/or cobalt was found in only $37.3 \%$ of the subjects with a history of metal dermatitis. In two previous studies, contact allergy to metals was found in $58 \%$ and $70 \%$ respectively, of women with a history of metal dermatitis $(4,5)$. A study by Boss \& Menné (144) indicates that a history of metal dermatitis is relevant in most cases. They found that although 
only $5 / 13$ women with a history of metal dermatitis were allergic to nickel, 12/13 developed dermatitis when exposed to the suspected ear ring for 48 hours. The irritant effect of nickel is one possible explanation for the non-allergic cause of metal dermatitis (146). Patients in the present study were mainly women with optimal exposure to metals through pierced ears. Furthermore, atopics were overrepresented. In two recent studies it has been shown that a positive history of metal dermatitis with negative test is common in atopics $(147,148)$. These facts may explain the high figure for non-allergic metal dermatitis.

Contact urticaria and hand eczema. Contact urticaria with a whealand-flare reaction on normal skin is easily recognized by an exposed individual and if possible he/she should avoid eliciting agents. However, contact urticaria does not always appear in the form of a distinct whealing reaction. In non-immunological contact urticaria, the concentration and nature of the urticariogenic substances particularly influence the strength of the reaction. A low, suboptimal concentration may provoke erythema, while a high concentration may provoke urticaria (79). Sometimes repeated exposure may be necessary (113). Exposure of dermatitic skin may elicit contact urticaria and thus the urticariogenic substances may be of clinical relevance for dermatitic but not for normal skin (88-90). The case histories of some patients indicated that contact urticaria was relevant only for dermatitic skin on the hands. 
Prick tests have been performed to trace urticariogenic substances in the present study. A prick test should be interpreted as positive only with caution. However, substances which produce a positive prick test do have urticariogenic properties which may be of clinical relevance, especially in dermatitic skin if exposure is optimal.

In patients with a history of contact urticaria, prick testing was carried out for two different reasons. Firstly, anamnestically suspected agents were tested, and secondly a screening series was carried out with substances in common use at the hospital. The relevance of the positive reactions varies according to the two reasons for testing. When the test was motivated by the history, a positive result was relevant for contact urticaria. Judging the relevance of a positive prick test in the series is difficult. Some patients with a positive test did have a positive history, and for them the relevance seems obvious. In subjects with a negative history, a positive test is probably of less clinical significance. Some patients may, however, have had signs of weak immediate reactions on eczematous skin which have not been recognized as contact urticaria.

Most reports of contact urticaria are limited to one or a few cases. Little is known about the prevalence and the relevance in different populations with hand eczema (8). Figures in the present study indicate that contact urticaria may be common. Most of the different kinds of food which produced positive prick tests in this study are known from the literature to provoke contact urticaria. 
Formaldehyde has been reported as a cause (113-115). A prick test with formaldehyde $0.1-0.6 \%$ produced a weak reaction in the study by Anderson \& Maibach (113). The high concentration used in this study may explain the high frequency of positive tests. A laboratory assistant with occupational exposure to formaldehyde was the only patient with a relevant prick test.

Rubber is another well-known urticariogenic substance (116119). Apart from natural latex, the glove tested contained zincdiethyl-dithiocarbamate $(Z D C)$ which may induce contact urticaria (120). The high frequency of positive prick tests may indicate a non-immunological urticariogenic effect of the glove. This is based on the fact that substances with non-immunological urticariogenic properties give rise to contact urticaria in a large number of exposed individuals (79). This view is supported by the common occurrence of skin complaints in connection with this particular glove. Apart from the rubber glove, few positive prick tests to the complex chemicals were found. Most of them contained one or more substances known to elicit contact urticaria. Further investigations are needed to identify the substance responsible and to clarify the nature and clinical significance of the positive tests found.

Staphylococcus aureus in hand eczema. This study shows that hand eczema in atopics as well as in non-atopics is regularly colonized by $\underline{S}$. aureus in quantities similar to those found in atopic dermatitis (105). Severe atopic dermatitis has shown higher densities of $\underline{S}$. aureus in some investigations $(104,149)$. Colonization by $\underline{S}$. 
aureus seems to parallel the severity of the eczema and clinical signs of pyoderma are lacking in most cases in spite of $\underline{S}$. aureus counts $>10^{5} \mathrm{cfu} / \mathrm{cm}^{2}$. Absence of clinical pyoderma in spite of high counts of $S$. aureus has also been found in studies on atopic dermatitis $(104,105)$.

The densities of $\underline{S}$. aureus after topical treatment with a potent corticosteroid were equal in normal skin and healing eczematous lesions and were similar to those found by McBride et al. (97) on the skin of normal hands. The density of other aerobes and anaerobes did not differ between eczematous lesion and normal skin before treatment and no significant changes were caused by the topical corticosteroid. These findings are in agreement with a study by Chan et al. (150) in which no significant difference in the microflora of normal skin was caused by the application of triamcinolone acetonide compared to white petrolatum base. The

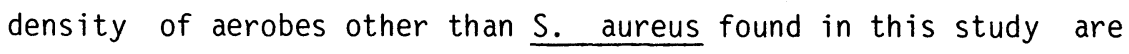
similar to previous findings on the palms of healthy individuals (151).

All isolations of a lipophilic corynebacteria in our study were obtained from non-atopics. This is in accordance with a study by Aly et al. (105) on atopic dermatitis where no lipophilic corynebacteria were found in the lesions and very few on normal skin. From these observations it seems possible that atopic skin might differ from non-atopic skin in its colonization. by lipophilic corynebacteria. 
Intermittent treatment with clobetasol propionate during 14 days produced a highly significant reduction and sometimes elimination of $\underline{S}$. aureus. A study by Leyden \& Kligman (149) on atopic dermatitis showed a slight but non-significant reduction of $\underline{S}$. aureus after one week's treatment with $0.25 \%$ fluocinolone acetonide. The higher mean count of $S$. aureus, the less potent steroid and the shorter treatment period in their study are all possible explanations for the difference found. Our findings also contrast with those of Marples, Rebora \& Kligman (152) who studied the effect of triamcinolone acetonide $0.1 \%$ on the growth of a single S. aureus strain which had been inocculated in experimental skin lesions. This study found that the steroid suppressed the experimental lesions but did not influence the multiplication of the bacteria.

Normal skin has an efficient defence against foreign microorganisms. Many different mechanisms are of importance in this defence. In the eczematous lesion one or more of the defense mechanisms may be disturbed and favour the colonization of bacteria (153). The reason for the selective, heavy colonization of $\underline{S}$. aureus in hand eczema is unknown. It is well-known, however, that protein $A$ in the cell wall of $S$. aureus has a high affinity to IgG (154) and to fibronectin (155). Both IgG and fibronectin might be present in eczematous lesions, which in turn could favour staphylococcal colonization and multiplication. Therefore a suppression of the eczematous inflammation by the potent topical corticosteroid may eliminate the prerequisites for the colonization of $S$. aureus and offer a possible interpretation of our results. 
Corticosteroids in therapeutic concentrations have been reported to inhibit the metabolism of certain microorganisms including S. aureus (156). However, this explanation is less likely since we were unable to demonstrate an inhibition of the growth in

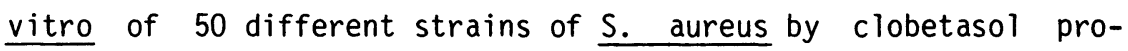
pionate in the dose range $16-2000 \mathrm{mg} / \mathrm{ml}$. 


\section{SUMMARY AND CONCLUSIONS}

1. The odds for developing hand eczema in wet occupations dominated by women (nursing/kitchen/cleaning work) was only approximately twice that of dry office work. Most eczemas even in wet work were mild and periodic and only a few gave rise to sickleave. Many sufferers could handle the disorder using selftreatment measures.

2. An increase in the irritant domestic load on women's hands through nursing babies and the simultaneous lack of a dish-washing machine will increase the risk of hand eczema as much as a wet work.

3. A history of atopic dermatitis increased the odds of developing hand eczema approximately three times both in wet and in dry work. As a single factor information about previous atopic dermatitis was of limited value as a predictor of the risk of developing hand eczema.

4. For women with a previously manifested disposition towards hand eczema, the odds of developing hand eczema was 12.9 times higher than for those with no previous hand eczema if they go into wet hospital work. This increase in the risk of hand eczema was great and created a subdivision of atopics and non-atopics in a high risk group and a normal-risk group. Half the subjects with atopic dermatitis, one quarter of the subjects with atopic mucosal symptoms and one fifth of the non-atopics belonged to this high 
risk group. This finding indicated that among atopics as well as non-atopics there are two subgroups which differ considerably regarding the risk of developing hand eczema.

5. A history of metal dermatitis increased the odds of developing hand eczema by a factor of 1.8. This increase was seen in individuals in one high risk and one normal risk level. Metal dermatitis may develop as a cause of contact allergy and probably through the irritant or other effects of metals. Metal dermatitis was more common in subjects with vulnerable skin.

6. Information about atopic disease as a supplement to information about previous hand eczema and metal dermatitis was of very limited value when predicting the risk of developing hand eczema in women who start wet work. One important observation was however that subjects with previous atopic dermatitis will suffer from a more severe hand eczema.

7. By means of simple anamnestic information about earlier hand eczema, metal dermatitis and atopic disease it was possible to obtain a very differentiated prognostic information about hand eczema and its consequences in women in wet hospital work.

8. In wet work employees with a disposition to hand eczema who seek medical advice for current hand eczema, trivial irritants in wet and domestic work played an important part in the etiology of the current hand dermatitis. Contact allergy and contact urticaria were fairly common. However, in most patients contact allergy and contact urticaria seemed to be of minor importance in the etiology of the hand eczema. 
9. Hand eczema was commonly colonized by $\underline{S}$. aureus in high counts in atopics as well as in non-atopics. The density of S. aureus was high even if the eczema showed no signs of clinical infection. Successful topical treatment of the eczema with a potent corticosteroid significantly reduced or eliminated the colonization of S. aureus. 


\section{ACKNOWLEDGEMENTS}

I wish to express my sincere gratitude and appreciation to:

Associate professor Ove Bäck for his continuous, stimulating scientific guidance throughout these investigations. Without his positive criticism and encouraging support this work would never have been completed. It has been a privilege for me to have Ove as my supervisor and mentor.

Associate professor Lennart Gip, head of the department of dermatology, Sundsvall hospital, for his great interest and friendly support during this study.

Associate professor Bo Mikaelsson for unvaluable participation in the planning of the epidemiological part of the study.

My co-authors, Claes Henning, MD, Sture Andersson, PhD (in memorial), Marie-Louise Hjörleifsson, BS, for very pleasant and valuable collaboration.

Professor Sture Lidén and professor Sigfrid Fregert for important advice in the planning of this study.

Mrs Vivianne Enqvist for patient, excellent secretarial assistance and for her always friendly and helpful attitude to the work. Her skilful typing and never ending support have been a prerequisite for completing this study.

Ms Birgitta Lagerlind and Mrs Siv Carlsson for unvaluable secretarial work with the numerous questionnaires.

Mrs Ulla Berg for skilful testing of the patients.

Associate professor Hans Nyquist for statistical assistance.

Colleagues and nurses at the Occupational Health Care of Västernorrland for their extremely valuable contribution to this study.

Colleagues and staff at the Department of Dermatology, Sundsvall Hospital and the Department of Dermatology, University Hospital, Umeå for constant encouragement.

My wife Ingrid and my daughters Karin and Helena for all their patience, love and support through all the years.

This investigation was made possible by generous grants from the Swedish Work Environment Fund (ASF) 79/58. 


\section{REFERENCES}

1. Agrup G. Hand eczema and other hand dermatoses in south Sweden. Acta Derm Venereol (Stockh) 1969;49 suppl 61.

2. Peltonen L. Nickel sensitivity in the general population. Contact Dermatitis 1979;5:27-32.

3. Kavli G, Førde $\mathrm{OH}$. Hand dermatoses in Troms $\varnothing$. Contact Dermatitis $1984 ; 10: 174-177$.

4. Lantinga $H$, Nater JP, Coenraads PJ. Prevalence, incidence and course of eczema of the hands and forearms in a sample of the general population. Contact Dermatitis 1984;10:135139.

5. Menné T, Borgan 0, Green A. Nickel allergy and hand dermatitis in a stratified sample of the Danish female population: an epidemiological study including a statistic appendix. Acta Derm Venereol (Stockh) 1982; 62:35-41.

6. Lammintausta $K$. Risk factors for hand dermatitis in wet work. Academic dissertation, Turku, 1982.

7. Rook A, Wilkinson DS, Ebling FJG (eds). Textbook of dermatology, 3rd edition. 0xford: Blackwell Sci Publ, 1979:329-331.

8. Epstein E. Hand dermatitis: practical management and current concepts. J Am Acad Dermatol 1984;10:395-424.

9. Rystedt I. Hand eczema and long-term prognosis in atopic dermatitis. Acta Derm Venereol (Stockh) 1985;65 supp1 117.

10. Edfors-Lubs ML. Allergy in 7000 twin pairs. Acta Allergol $1971 ; 26: 249-285$.

11. Kjellman M. Atopic disease in 7-year-old children. Acta Pediatr Scand 1977;66:465-471.

12. Besnier E. Premiére note et observations préliminaire pour servir d'introduction à l'etude des prurigos diathésiques. Ann Dermatol Syphiligr 1892;3:634-648.

13. Coca AF, Cooke RA. On the classification of the phenomena of hypersensitiveness. J Immunol 1923;8:163-182.

14. Prausnitz $C$, Küstner $H$. Studien über die überempfindlichkeit.Zbl Bact 1921;86:160-169.

15. Ischizaka K, Ischizaka T, Hornbrook MM. Physicochemical properties of reaginic antibody. V. Correlation of reaginic activity with E-globulin antibody. J Immunology 1966;97:840853. 
16. Johansson SGO. Raised levels of a new immunoglobulin class (IgND) in asthma. Lancet 1967; i i:951-953.

17. Rowe DS, Tackett L, Bennich H, Ischizaka K, Johansson SG0, Andersson SG. A research standard for human serum immunoglobulin E. Bulletin of the World Health Organization 1970;43: 609-611.

18. Johansson SGO, Bennich $H$, Berg $T$. The clinical significance of IgE. Progr Clin Immunol 1972;1:157-168.

19. Johansson SGO. In vitro diagnosis of reagin mediated allergic diseases. Allergy 1978;33:282-298.

20. Hanifin J. Atopic dermatitis. J Am Acad Dermatol 1982;6:113.

21. Atherton DJ. Allergy and atopic eczema I. Clin Exp Dermatol $1981 ; 6: 191-203$.

22. Oohman S, Juhlin L, Johansson SGO. Immunoglobulins in atopic dermatitis. Excerpta Med"1972;119-126.

23. Hanifin JM, Rajka G. Diagnostic features of atopic dermatitis. Acta Derm Venereol (Stockh) 1980;60 suppl 92:44-47.

24. Bandmann HJ, Agathos M. Die atopische Handdermatitis. Dermatosen in Beruf und Umwelt 1980;28:110-113.

25. Glickman FS, Silvers SH. Hand eczema and atopy in housewives. Arch Dermatol 1967;95:487-489.

26. Cronin E, Bandmann HJ, Calnan CD, Fregert S, Hjorth $\mathrm{N}$, Magnusson B, Maibach HI, Malten K, Meneghini CL, Pirilä V, Wilkinson DS. Contact dermatitis in the atopic. Acta Derm Venereol (Stockh) 1970;50:183-187.

27. Breit R, Leutgeb Ch, Bandmann HJ. Zum neurodermitischen Handekzem. Arch Dermatol Forsch 1972;244:353-354.

28. Forsbeck M, Skog E, Assbrink E. Atopic hand dermatitis: A comparison with atopic dermatitis without hand involvement, especially with respect to influence of work and development of contact sensitization. Acta Derm Venereol (Stockh) 1983;63:9-13.

29. Wilkinson DS, Bandmann HJ, Calnan CD, Cronin E, Fregert $S$, Hjort N, Magnusson B, Maibach HI, Maiten KE, Meneghini CL, Pirilä V. The role of contact allergy in hand eczema. Trans St John's Hosp Dermatol Soc 1970;56:19-25.

30. Rook A, Wilkinson DS, Ebling FJG (eds). Textbook of dermatology, 3rd ed, Oxford: Blackwell Sci Publ, 1979:363. 
31. Dowling GB, Naylor PFD. Defence mechanisms of the skin against alkaline substances. Trans St John's Hosp Dermatol Soc $1960 ; 44: 12-34$.

32. Kligman AM. The biology of the Stratum Corneum. In: The Epidermis. Ed: Montagna W \& Lobitz WC Jr. New York, Academic Press. 1964:387-433.

33. Epstein W, Maibach HI. Cell renewal in human epidermis. Arch Dermatol 1965;92:462-468.

34. Weinstein GD, Van Scott EJ. Autoradiographic analysis of turnover times of normal and psoriatic epidermis. J Invest Dermatol 1965;45:257-262.

35. Smeenk G. The influence of detergents on the skin: a clinical and biochemical study. Arch Klin Exp Dermatol $1969 ; 235: 180-191$.

36. Smeenk G, Polano MK. Methods for comparative estimation of the irritancy of various detergents on human skin. Trans St John's Hosp Dermatol Soc 1965;51:220-232.

37. Blank IH. Cutaneous barriers. J Invest Dermatol 1965;45:249256.

38. Blank IH. The mechanism of the action of soaps and detergents on the skin. In: The Evolution of Therapeutic Agents and Cosmetics. Ed. Sternberg TH \& Newcomer VD.New York, Mc Graw-Hi11, 1964:80-85.

39. Middleton JD. The mechanism of action of surfactants on the water binding properties of isolated stratum corneum. J Soc Cosmet Chem 1969;20:399-412.

40. Middleton JD. The mechanism of water binding in stratum corneum. Br J Dermatol 1968;80:437-450.

41. Rook A, Wilkinson DS, Ebling FJG (eds). Textbook of dermatology, 3rd ed, Oxford: Blackwell Sci Publ, 1979:364.

42. Malten KE, Spruit D, Boemaars HD et al: Horny layer injury by solvents. Berufsdermatosen 1968;16:135-147.

43. Shahidullah M, Raffle EJ, Rimmer AR, Frain-Bell W. Transepidermal water loss in patients with dermatitis.

$\mathrm{Br} J$ Dermatol 1969:81:722-730.

44. Spruit D, Malten KE. Estimation of the injury of human skin by alkaline liquids. Berufsdermatosen 1968;16:135-147.

45. Hagerman G. 'Traumiterative' (toxic) eczema. Dermatologica $1957 ; 115: 525-529$.

46. Fregert $S$. Occupational dermatitis in a 10-year material. Contact Dermatitis 1975;1:96-107. 
47. Stagis H. Occupational dermatitis among hospital cleaners. Academic dissertation, University of Aarhus, Aarhus 1976.

48. Calnan $C D$, Bandmann $H J$, Cronin E, Fregert $S$, Hjorth $N$, Magnusson B, Malten K, Meneghini CL, Pirilä V, Wilkinson DS. Hand dermatitis in housewives. Br J Dermatol 1970;82:543548 .

49. Marks R, Cronin E. Hand eczema in hairdressers. Australas J Dermatol 1977;18:123-126.

50. Cronin E, Kullivanijaya P. Hand dermatitis in hairdressers. Acta Derm Venereol (Stockh) 1979:59 suppl 85:47-50.

51. Björnberg A. Skin reactions to primary irritants in patients with hand eczema. Isacsons Tryckeri, Gothenburg 1968.

52. Kligman AM, Wooding WM. A method for the measurement and evaluation of irritants on human skin. J Invest Dermatol 1967;49:78-94.

53. Kligman AM, Epstein W. Updating the maximization test for identifying contact allergens. Contact Dermatitis 1975;1: 231-239.

54. Jordan WP. Allergic contact dermatitis in hand eczema. Arch Dermatol 1974;110:567-569.

55. Rook A, Wilkinson DS, Ebling FJG (eds). Textbook of dermatology, 3rd ed, Oxford: Blackwell Sci Publ, 1979:481.

56. Palacios J, Fuller EW, Blaylock WK. Immunological capabilities of patients with atopic dermatitis. J Invest Dermatol $1966 ; 47: 484-490$.

57. Rajka G. Delayed dermal and epidermal reactivity in atopic dermatitis (Prurigo Besnier). Acta Derm Venereol (Stockh) 1967; $47: 158-163$.

58. Rajka G. Atopic Dermatitis. Vol 3 in the series of Major Problems in Dermatology. VB Saunders Company Ltd., London, Philadelphia, Toronto 1975.

59. Grove DI, Reid JG, Forbes I. Humoral and cellular immunity in atopic eczema. Br J Dermatol 1975;92:611-618.

60. Blaylock WK. Atopic dermatitis: Diagnosis and pathobiology. J Allergy Clin Immunol 1976;57:62-79.

61. Angelini $G$, Meneghini $C L$. Contact and bacterial allergy in children with atopic dermatitis. Contact Dermatitis 1977;3: 163-174. 
62. Epstein WL, Kligman AM. Some factors affecting the reaction of allergic contact dermatitis. J Invest Dermatol 1959;33: 231-243.

63. Lowney ED. Attenuation of contact sensitization in man. $J$ Invest Dermatol 1968;50:244-249.

64. Rogge JL, Hanifin JM. Immunodeficiences in severe atopic dermatitis. Arch Dermatol 1976;112:1391-1396.

65. Jones HE, Lewis CW, Mcmarlin SL. Allergic contact sensitivity in atopic dermatitis. Arch Dermatol 1973;107: 217-222.

66. Epstein S, Mohajerin AH. Incidence of contact sensitivity in atopic dermatitis. Arch Dermatol 1964;90:284-287.

67. Rudzki E, Grzywa Z. Contact sensitivity in atopic dermatitis. Contact Dermatitis 1975;1:285-287.

68. Bandmann HJ, Breit R, Leutgeb C. Kontaktallergie und Dermatitis atopica. Arch Invest Dermatol 1972;244:332- 339.

69. Epstein S. Contact dermatitis due to nickel and chromate. Arch Dermatol 1956;23:236-255.

70. Dobson RL. Discussion. J Invest Dermatol 1963;41:416-418.

71. Watt TL, Baumann RR. Nickel earlobe dermatitis. Arch Dermatol $1968 ; 98: 155-158$.

72. Calnan CD. Nickel dermatitis. Br J Dermatol 1956;68:229-236.

73. Caron GA. Nickel sensitivity and atopy. $\mathrm{Br} J$ Dermatol $1964 ; 76: 384-387$.

74. Wilson HTH. Nickel dermatitis. The Practitioner 1956;177: 303-308.

75. Peltonen L. Atopia ja nikkeliallergia. Academic Dissertation, University of Turku, Turku, 1979.

76. Maibach HI, Johnson HL. Contact urticaria syndrome. Contact urticaria to diethyltoluamide. Arch Dermatol 1975;111:726730 .

77. von Krogh G, Maibach $H$. The contact urticaria syndrome 1982. In: Kligman AM, Leyden JJ, eds.: Safety and efficacy of topical drugs and cosmetics. Grune \& Stratton, New York 1982:249-267.

78. Monroe EW, Jones HE. Urticaria. An updated review. Arch Dermatol 1977;113:80-90.

79. Lahti A. Non-immunologic contact urticaria. Acta Derm Venereol (Stockh) 1980;60 suppl 91. 
80. Roupe G, Strannegaard 0. Anaphylactic shock elicited by topical administration of Bacitracin. Arch Dermatol 1969; 100:450-452.

81. Henry JC, Tschen EH, Becker LE. Contact urticaria to parabens. Arch Dermatol 1979;115:1231-1232.

82. Schmidt H. Contact urticaria. Contact Dermatitis 1978:4:230232.

83. Zschunke E. Contact urticaria, dermatitis and asthma from cockroaches. Contact Dermatitis 1978;4:313-314.

84. Bernstein IL, Englander BE, Gallagher JS et al. Localized and systemic hypersensitivity reactions to human seminal fluid. Ann Intern Med 1981;94:459-465.

85. Pepys J. Clinical and therapeutic significance of patterns of allergic reactions of the lungs to extrinsic agents. Am Rev Resp Dis 1977;116:573-588.

86. Monroe EW. Urticaria. Int J Derm. 1981;20:32-41.

87. von Krogh G, Maibach HI. The contact urticaria syndrome - an updated review. J Am Acad Dermatol 1981; 5:328-342.

88. Hjorth $\mathrm{N}$, Roed-Petersen J. Occupational protein contact dermatitis in food handlers. Contact Dermatitis 1976;2:2442 .

89. Krook G. Occupational dermatitis from Lactuca saliva (lettuce) and Chicorium (endive). Simultaneous occurrence of immediate and delayed allergy as a cause of contact dermatitis. Contact Dermatitis $1977 ; 3: 27-36$.

90. Maibach H. Immediate hypersensitivity in hand dermatitis. Role of food-contact dermatitis. Arch Dermatol 1976;112: 1289-1291.

91. Andersen KE, Lowenstein $H$. An investigation of the possible immunological relationship between allergen extracts from birch pollen, hazelnut, potato and apple. Contact Dermatitis 1978; 4:73-79.

92. Noble WC. Microbiology of human skin, 2nd ed. Lloyd Luke Ltd, London 1981:67-73, 114-119, 166, 208, 229, 353-354.

93. Henning $C$, Hillborgh U, Lindvall K, Marqvardsen 0 , Sellers $J$, Wahl in S, Ransjö U. Comparison of Staphylococcus aureus carriage and skin infection rates in hospital and office employees. J Hyg (Camb) 1979;83: 437-444.

94. Noble WC, Valkenburg HA, Wolters CHL. Carriage of Staphylococcus aureus in random samples of a normal population. J Hyg (Camb) 1967;65:567-573. 
95. Polakoff S, Richards IDG, Parker MT, Lidwell OM. Nasal and skin carriage of Staphyloocuccus aureus by patients undergoing surgical operation. J Hyg (Camb) 1967;65:559-566.

96. Noble WC. Ward infections. Trans St John's Hosp Dermatol Soc $1968 ; 54: 83-88$.

97. McBride ME, Montes LF, Fahlberg WJ, Knox JM. Microbial flora of nurses' hands. III. The relationship between staphylococcal skin populations and the persistence of carriage. Int $\mathrm{J}$ Dermatol 1975;14:129-135.

98. Nilsson E, Henning $C$. The bacteriological flora in candidiosis of the skin. Curr Ther Res 1977;22:27-32.

99. Aly R, Maibach HI, Mandel A. Bacterial flora in psoriasis. Br J Dermatol 1976;95:603-606.

100. Marples RR, Heaton CL, Kligman AM. Staphylococcus aureus in psoriasis. Arch Dermatol 1973;107:568-570.

101. Noble WC, Savin JA. Carriage of Staphylococcus aureus in psoriasis. Brit Med J 1968;1:417-418.

102. Selwyn S. Bacterial infections in a skin department. $\mathrm{Br} J$ Dermatol 1963;75:26-28.

103. Leyden JJ. Antibiotic usage in dermatological practice. Int $\mathrm{J}$ Dermatol 1974;13:342-352.

104. Leyden JJ, Marples RR, Kligman AM. Staphylococcus aureus in the lesions of atopic dermatitis. Br J Dermatol 1974;90:525530 .

105. Aly R, Maibach HI, Shinefeld HR. Microbial flora of atopic dermatitis. Arch Dermatol 1977;113:780-782.

106. Maddala GS. Limited - dependent and qualitative variables in econometrics. Cambridge University Press, 1983.

107. Williamson P, Kligman AM. A new method for the quantitative investigation of cutaneous bacteria. J Invest Dermatol $1965 ; 6: 498-503$.

108. Holdeman LV, Cato EP, Moore WEC. Anaerobe laboratory manual, ed 4. Virginia Polytechnic Institute, Blacksburg, Virginia, 1977.

109. Kloos WE, Schleifer KH. Simplified scheme for routine identification of human Staphylococcus species. J Clin Microbiol $1975 ; 1: 82-88$.

110. Schleifer KH, Kloos WE. A simple test system for the separation of staphylococci from micrococci. J Clin Microbiol 1975;3:337-338. 
111. Smith RF. Characterization of human cutaneous lipophilic diphteroids. J Gen Microbiol 1969;55:433-443.

112. Nie NH, Hull CH, Jenkins JG et al. Statistical package for the social sciences, ed. 2. McGraw-Hill, New York, 1975.

113. Andersen KE, Maibach HI. Multiple application delayed onset contact urticaria: possible relation to certain unusual formalin and textile reactions? Contact Dermatitis 1984;10: 227-234.

114. Helander I. Contact urticaria from leather containing formaldehyde. Arch Dermatol 1975;111:726-730.

115. Lindskov R. Contact urticaria to formaldehyde. Contact Dermatitis $1982 ; 8: 333-334$.

116. Nutter AF. Contact urticaria to rubber. Br J Dermatol 1979: 101:597-598.

117. Förström L. Contact urticaria from latex surgical gloves. Contact Dermatitis 1980;6:33-34.

118. Kleinhans D. Contact urticaria to rubber gloves. Contact Dermatitis $1984 ; 10: 124-125$.

119. Meding B, Fregert S. Contact urticaria from natural latex gloves. Contact Dermatitis 1984;10:52-53.

120. Helander I, Mäkele A. Contact urticaria to zinc diethyldithiocarbamate (ZDC). Contact Dermatitis $1983 ; 4: 327-328$.

121. Rudzki E, Gryzwa Z. Immediate reaction to balsam of Peru, cassia oil and ethyl vanillin. Contact Dermatitis 1976;2: 360-361.

122. Forsbeck $M$, Skog $E$. Immediate reactions to patch tests with balsam of Peru. Contact Dermatitis 1977;3:201-205.

123. Fisher AA. Contact dermatitis, 2nd ed. Lea \& Febiger, Philadelphia, 1973:283-286.

124. Gaul LE. Dermatitis from cethyl and stearyl alcohol. Arch Dermatol 1969;99:593.

125. Pearson RSB. Potato sensitivity: an occupational allergen in housewives. Acta Allergol 1966;21:507.

126. Rostenberg A Jr. Contact urticaria from food. Arch Dermatol 1970;101:491.

127. Cronin E. Immediate-type hypersensitivity to potato. Contact Dermatitis News letter 1973;13:358. 
128. Fisher AA. Allergic 'protein' contact dermatitis due to food. Cut is 1975;16:793.

129. Hannuksela $M$, Lahti $A$. Immediate reactions to fruits and vegetables. Contact Dermatitis $1977 ; 3: 79-84$.

130. Van Ketel WG. Skin eruptions caused by vegetables and fruit including pears. Contact Dermatitis $1982 ; 8: 352$.

131. Herrmann F, Sulzberger MB, Baer RL. Prevention of allergens into the human skin. N.Y. State J Med 1944; 44:2452.

132. Edwards EK. Contact urticaria to cow's milk. Cutis $1981 ; 28$ : 450-451.

133. Fisher AA. Allergic contact urticaria to raw beef: histopathology of the specific wheal reaction at the scratch test site. Contact Dermatitis 1982;8:425.

134. Beck HI, Knudsen Nissen B. Type-1 reactions to commercial fish in non-exposed individuals. Contact Dermatitis 1983;9: 219-223.

135. Beck HJ, Knudsen Nissen B. Contact urticaria to commercial fish in atopic persons. Acta Derm Venereol (Stockh) 1983:63: 257-260.

136. Hjorth $\mathrm{N}$, Roed-Petersen J. Allergic contact dermatitis in veterinary surgeons. Contact Dermatitis 1980;6:27-29.

137. Dahlquist I, Fregert S. Occupational dermatoses in hospital personnel. Berufsdermatosen 1970;18:261-268.

138. Barregård L, Stenberg B. Arbetsrelaterade handeksem hos sjukhuspersonal. Läkartidningen 1982;79:1355-1356.

139. Shmunes E, Keil JE. Occupational dermatoses in South Carolina: $A$ descriptive analys is of cost variables. J Am Acad Dermatol 1983;9:861-866.

140. Malten KE. Thoughts on irritant contact dermatitis. Contact Dermatitis $1981 ; 7: 238-247$.

141. Fregert S. Manual of contact dermatitis. 1st ed, Munksgaard, Copenhagen 1974:38-40.

142. Peltonen L. Nickel sensitivity. An actual problem. Int $J$ Dermatol 1981;30:342-353.

143. Christensen $O B$. Prognosis in nickel allergy and hand eczema. Contact dermatitis 1982;8:7-15.

144. Boss A, Menné T. Nickel sensitization from ear piercing. Contact Dermatitis 1982;8:211-213. 
145. Larsson-Stymne B, Widström L. Nickelallergi hos skolflickor - en följd av håltagning i öronen? Läkartidningen 1983;80: 2973-2974.

146. Wahlberg JE, Wahlberg E. Skin irritancy from nickel sulfate and test patches. Contact Dermatitis 1985;13: 224225.

147. Fischer T, Rystedt I. False-positive, follicular and irritant patch test reactivity to metal salts. Contact Dermatitis $1985 ; 12: 93-98$.

148. Möller $H$, Svensson $\AA$. Metal sensitivity: positive history but negative test indicates atopy. Contact Dermatitis $1986 ; 14: 57-60$.

149. Leyden JJ, Kligman AM. The case for steroid-antibiotic combinations. Br J Dermatol 1977:96:179-187.

150. Chan HL, Aly R, Maibach HI. Effect of topical corticosteroid on the microbial flora of human skin. J Am Acad Dermatol 1982;7:346-348.

151. Noble WC. Microbiology of human skin, 2nd ed, Lloyd Luke Ltd, London 1981:71.

152. Marples RR, Rebora A, Kligman AM. Topical steroid-antibiotic combinations. Arch Dermatol 1973;108:237-240.

153. Noble WC. Microbiology of human skin, 2nd ed, Lloyd Luke Ltd, London 1981;3-106.

154. Forsgren A, Sjöquist J. "Protein A" from S. aureus I. Pseudo-immune reaction with human $\gamma$-globulin. J Immunol $1966 ; 97: 822-827$.

155. Rydén C, Rubin K, Speziale $P$ et al. Fibronectin in receptors from Staphylococcus aureus. J Biol Chem 1983;258:3396-3401.

156. Raab W. Effects of local corticosteroids in skin infections. Dermatologica 1976;152 Supp 1 1:67-79. 
